\title{
A Comparative in vivo Study between the Conventional Method and Diode Lasers in Treatment of Gingival Pigmentation
}

\author{
${ }^{1}$ Chellavignesh Sathyanarayanan, ${ }^{2}$ Vidyaa Hari lyer
}

\begin{abstract}
Esthetic dentistry has positively influenced the overall appearance of an individual and contributed to an enhancement of psychological factors, such as self-esteem, self-confidence and a boost in one's lifestyle. Gingival color is attributed by the presence or absence of the melanocytes which is present in the basal layer of the epithelium. An increase in the number of melanocytes along with increase in production of melanin (a dark colored pigment) contribute to the dark hue of the gingival color. Such hyperpigmentation is unesthetic which indirectly brings down the smile and confidence in a person. This article aims to bring the effectiveness of laser treatment by a comparative in vivo study between the conventional methods (use of abrasives) vs $940 \mathrm{~nm}$ diode soft tissue lasers in the same patient in two quadrants of their mouth. Ten patients aged between 18 and 21 years were taken into the study. This study also emphasized the psychological factors in addition to the advantage of the treatment using lasers which has made dentistry a pleasurable experience for the patient and the dentist.
\end{abstract}

Keywords: Dental lasers, Gingival depigmentation, Esthetic dentistry, Racial gingival hyperpigmentation, Pain-free dentistry.

How to cite this article: Sathyanarayanan C, lyer $\mathrm{VH}$. A Comparative in vivo Study between the Conventional Method and Diode Lasers in Treatment of Gingival Pigmentation. Int J Laser Dent 2014;4(1):8-19.

Source of support: Nil

Conflict of interest: None declared

\section{INTRODUCTION}

Gingival pigmentation is contributed by the melanocyte in the basal layer of the epithelium and thickness of the epithelium (gingival biotype) along with the underlying capillaries. The melanocytes that contain melanin (a black

\footnotetext{
${ }^{1}$ Student, ${ }^{2}$ Private Practitioner

${ }^{1}$ Tagore Dental College and Hospital, Chennai, Tamil Nadu India

${ }^{2}$ Fellowship and Diplomate in Laser Dentistry, Smile Dental Clinic, Chennai, Tamil Nadu, India

Corresponding Author: Vidyaa Hari lyer, Private Practitioner Fellowship and Diplomate in Laser Dentistry, Smile Dental Clinic Chennai, Tamil Nadu, India, Phone: 09840176088, e-mail: vidyaahari@gmail.com
}

colored pigment) give dendritic processes into the epithelium (Fig. 1) which gives dark hue to the gingiva. The general color of the gingiva is coral pink in nature. The causes for oral pigmentation include endocrine disturbances, Albright syndrome, malignant melanoma, antimalarial drugs, hemochromatosis, chronic obstructive pulmonary disease and racial pigmentation. Racial pigmentation is predominantly seen in southern India, parts of South Africa and Srilanka. In the south Indian population, due to increase production of melanin, the gingival color is characteristically light brown to chocolate brown in nature which is mainly due to racial pigmentation. The modern general population are concerned with the black color pigmented gingiva and want a comfortable, easy solution to this esthetic concern.

The conventional methods involved in removal of this pigmentation are epithelial abrasion using diamond abrasive, removal of epithelium as a peel by scalpel, ${ }^{1}$ electrocautery, cryosurgery and modern day with dental lasers. The lasers of choice to remove pigmentation are KTP lasers $(532 \mathrm{~nm})$, argon lasers $(488 \mathrm{~nm}, 510 \mathrm{~nm})$, diodes ${ }^{2-4}(810 \mathrm{~nm}, 940 \mathrm{~nm}$ and $980 \mathrm{~nm})$ and Nd:YAG ${ }^{5}(1060 \mathrm{~nm})$ which uses the concept of melanin pigment (chromophore) which absorbs the laser energy. The Erbium family ${ }^{6}$ (Er,Cr:YSGG-2780 nm and Er:YAG-2940 nm), however, ablates the gingiva using water as the chromophore. This article highlights the use of shorter wavelength lasers (940 $\mathrm{nm}$ diode) which is easily absorbed by the melanin along with the use of dia-mond abrasives in the same patient in different quadrants for a comparative study.

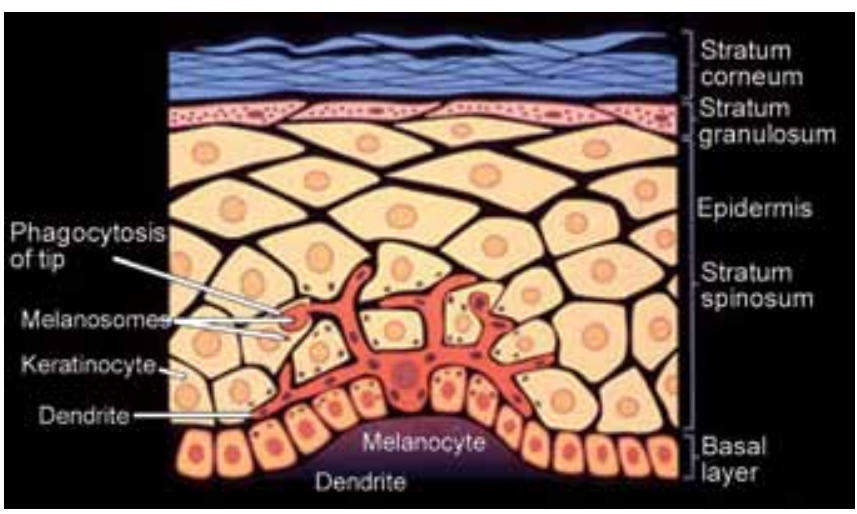

Fig. 1: Structure of the melanocyte with dendritic processes within the basal cell layer of epithelium 
Laser, an acronym for light amplification by the stimulated emission of radiation, was first used for dental application in 1960 by Theodore Maiman with a ruby laser. In 1962, Robert Hall invented the first diode laser. The significant properties of the laser are monochromatic (uni-color), collimated (the beams are parallel to each other) and coherence (in single phase). Therefore, being high in energy, the laser tissue interaction predominantly is absorption which is majorly used in clinical dentistry. Diode lasers are solid state semiconductor lasers. It is an excellent soft tissue ${ }^{7,8}$ versatile surgical tool which can be used as an alternative in most of the periodontal ${ }^{9-11}$ and surgical procedures which brings about precise and accurate cuts when used in contact mode. There is excellent hemostasis as the laser is highly absorbed by hemoglobin and melanin, and poorly in water and hydroxyapatite crystals.

\section{MATERIALS AND METHODS}

The following instrumentation and materials (Fig. 2) were used in this study:

- $400 \mu \mathrm{m}$ and $7 \mathrm{~mm}$ length disposable surgical tip.

- $940 \mathrm{~nm}$ diode laser and appropriate protective eye wear.

- Plastic mouth mirror, probe and tweezer.

- Cheek retractor.

- Local anesthetic solution-xicaine (2\% lignocaine hydrochloride and adrenaline bitartrate 1:80000, ICPA Health Products, India).

- Precaine topical gel (lidocaine $8 \%$, dibucaine $0.8 \%$ in flavored aqueous base, Pascal International, Bellevue, WA, USA).

- Nummit Spray (15\% lidocaine topical aerosol USP, ICPA, Mumbai, India).

- A pear-shaped diamond abrasive.

\section{Laser Equipment}

The application of laser in dentistry depends on various factors, such as the chromophore (pigment in the host tissue), the wavelength of the laser equipment, and the efficiency

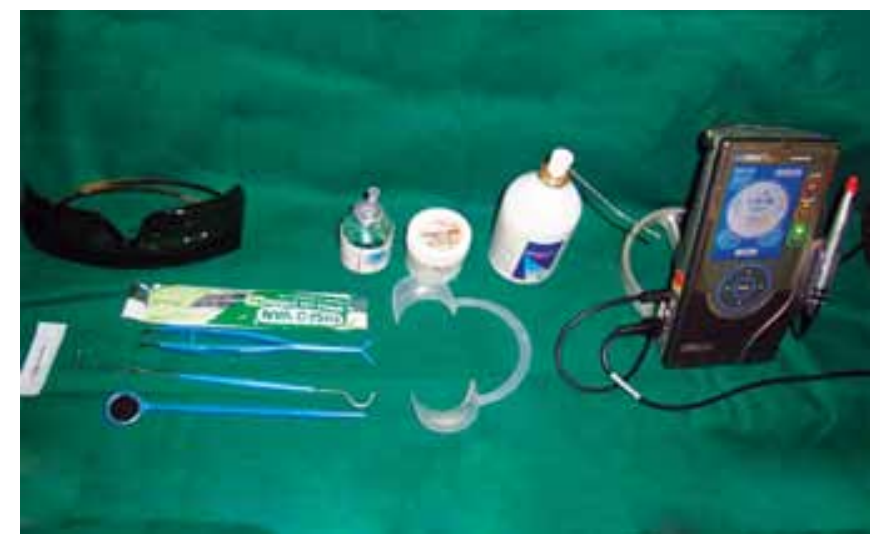

Fig. 2: Armamentarium used for the comparative study of the absorption and interaction of the laser to host tissue, maximum thermal relaxation in the host tissue with minimal power setting along with minimal collateral damage to the surrounding oral tissues. A $940 \mathrm{~nm}$ diode (Ezlase, Biolase, Irvine, CA, USA) class IV laser was used in this study. All laser safety precautions, such as wearing laser safety goggles, use of plastic nonreflective instrumentation, reducing traffic within the clinical operatory, use of laser hazard signs outside the operatory and management of the protocols within the operatory by the laser safety officer were followed.

\section{PROCEDURE}

The patients chosen for the study had racial discoloration of the gingiva which was an inclusion criterion. All the patients were periodontally healthy and nonsmokers. All other systemic conditions were ruled out. Sample selection was done taking a group of 10 patients between the age of 18 and 21 years, concerned with their pigmented gingiva and smile. Dummett-Gupta Oral Pigmentation Index 1964 was used to classify the pigmentation. Out of 10 patients, five were heavily pigmented, two were moderately pigmented and three had mild pigmentation.

All patients chosen for the study were explained about the protocol, had given an informed consent and agreed to be a part of the comparative study technique and the two modalities of treatment. They were informed about the recurrence of the pigmentation which could be anywhere between 6 and 18 months postoperatively. Scaling and polishing with oral prophylaxis was done and preoperative photographs (Figs 3A, 4A, 5A, 6A, 7A, 8A, 9A, 10A, 11A and $12 \mathrm{~A}$ ) were taken.

The upper jaw was divided into two quadrants. The first right side quadrant was anesthetized with local anesthetic injection and diamond abrasive was used to peel the outer epithelium (Figs 3B, 4B, 5B, 6B, 7B, 8B, 9B, 10B, 11B and $12 \mathrm{~B})$. The second left side quadrant was given a topical gel/ spray application if needed and treated with the help of lasers to bring about the depigmentation (Figs 3C, 4C, 5C, 6C, 7C,

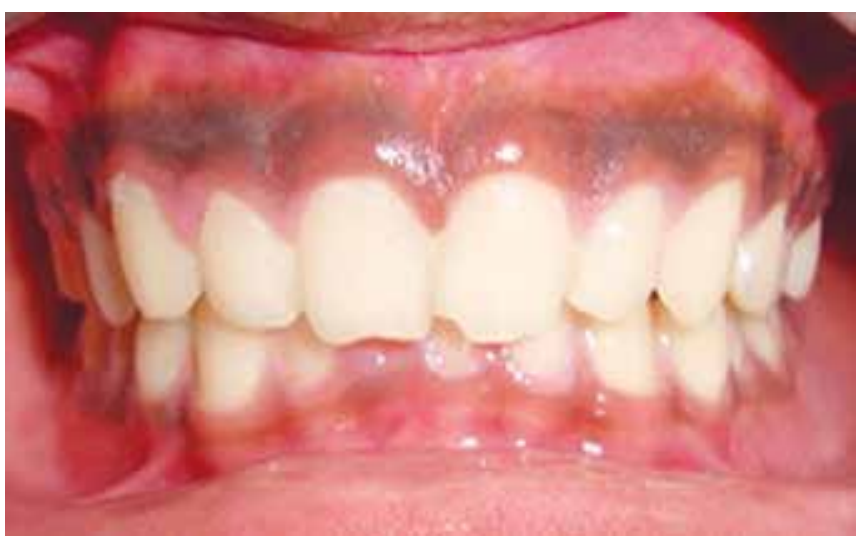

Fig. 3A: Preoperative view of the patient (Case 1) 
$8 \mathrm{C}, 9 \mathrm{C}, 10 \mathrm{C}, 11 \mathrm{C}$ and $12 \mathrm{C}$ ). The laser parameters and settings used were $1 \mathrm{~W}$, continuous wave, $400 \mu \mathrm{m} 7 \mathrm{~mm}$ long initiated surgical tip in contact mode (Fig. 13). Photographs were taken intraoperative and immediately after the procedure (Figs 3D, 4D, 5D, 6D, 7D, 8D, 9D, 10D, 11D and 12D). All patients were followed with 1 day, 1 month (Figs 3E, 4E, 5E, 6E, 7E, $8 \mathrm{E}, 9 \mathrm{E}, 10 \mathrm{E}, 11 \mathrm{E}$ and $12 \mathrm{E}$ ) and 6 months (Figs 3F, 4F, 5F, 6F, $7 \mathrm{~F}, 8 \mathrm{~F}, 9 \mathrm{~F}, 10 \mathrm{~F}, 11 \mathrm{~F}$ and $12 \mathrm{~F}$ ) postoperatively.

A tabular column was charted with the following evaluation criterion which was noted: level of gingival pigmentation, injection type used, bleeding, pain, redness, gingival color, wound healing comfort, postoperative discomfort, medications taken, treatment prognosis and recurrence of pigmentation in a span of 6 months (Table 1). This study also emphasized the psychological factors in addition to the advantage of the treatment using lasers (Table 2).

\section{DISCUSSION}

Lasers vs conventional methods have brought a lot of speculation in the field of modern high-tech ${ }^{12}$ dentistry. The objective of the study was to show the effect and use of laser ${ }^{13}$ as an alternative tool in depigmentation ${ }^{14}$ procedure and enlist the advantages of lasers ${ }^{15,16}$ over conventional procedures.

All patients were given local infiltration anesthesia in the right quadrant for conventional technique and all of them were scared and skeptical about getting the shot. However, only topical gel or spray if needed was used on the left quadrant. The minimization of injections and the immediate comfort felt by the patients, such as no numbness and/or feeling of a swelling on the left quadrant thrilled the patients. Lasers have a low level laser therapeutical ${ }^{17,18}$ effect and it numbs the region of laser tissue interaction without crossing the ablation threshold prior to the laser interaction with the chromophore in the host tissue.

Bleeding was seen in the right quadrant in all patients whereas the left side had absolutely no traces of blood. Studies by Mordon et al (2002) proved that lasers increase platelet activation at the point of the wound which leads to sealing of blood vessels. Nine out of 10 patients experienced pain in the conventional technique region whereas all of them were absolutely comfortable on the left quadrant. Studies by Pick et al (1985) have shown that lasers seal the

Table 1: Evaluation criteria on all 10 patients

\begin{tabular}{|c|c|c|c|c|c|c|c|c|c|c|c|c|c|c|c|c|c|c|c|c|}
\hline \multirow{2}{*}{$\begin{array}{l}\text { Evaluation criteria } \\
\text { on patients }\end{array}$} & \multicolumn{2}{|c|}{1} & \multicolumn{2}{|c|}{2} & \multicolumn{2}{|c|}{3} & \multicolumn{2}{|c|}{4} & \multicolumn{2}{|c|}{5} & \multicolumn{2}{|c|}{6} & \multicolumn{2}{|c|}{7} & \multicolumn{2}{|c|}{8} & \multicolumn{2}{|c|}{9} & \multicolumn{2}{|c|}{10} \\
\hline & $C$ & $L$ & $\bar{C}$ & $L$ & $C$ & $L$ & $C$ & $L$ & $C$ & $L$ & $C$ & $L$ & $C$ & $L$ & $C$ & $L$ & $C$ & $L$ & $C$ & $L$ \\
\hline Injection & + & - & + & - & + & - & + & - & + & - & + & - & + & - & + & - & + & - & + & - \\
\hline Bleeding & + & - & + & - & + & - & + & - & + & - & + & - & + & - & + & - & + & - & + & - \\
\hline Pain & + & - & + & - & + & - & + & - & + & - & + & - & + & - & + & - & + & - & - & - \\
\hline Redness & + & - & + & - & + & - & + & - & + & - & + & - & + & - & + & - & + & - & + & - \\
\hline Gingival color & - & + & - & + & - & + & - & + & - & + & - & + & - & + & - & + & - & + & - & + \\
\hline $\begin{array}{l}\text { Wound healing } \\
\text { comfort }\end{array}$ & - & + & + & + & - & + & + & + & - & + & - & + & - & + & + & + & + & + & + & + \\
\hline $\begin{array}{l}\text { Postoperative } \\
\text { discomfort }\end{array}$ & + & - & + & - & + & - & + & - & + & - & + & - & + & - & + & - & + & - & + & - \\
\hline Medications & + & - & - & - & - & - & - & - & + & - & + & - & - & - & + & - & - & - & + & - \\
\hline Treatment prognosis & + & + & + & + & + & + & + & + & - & + & - & + & + & + & - & + & + & + & + & + \\
\hline $\begin{array}{l}\text { Recurrence of } \\
\text { pigments in } \\
6 \text { months }\end{array}$ & + & - & - & - & + & - & - & - & - & - & + & + & - & - & - & - & - & - & - & - \\
\hline
\end{tabular}

Table 2: Psychological assessments of patients' response to the comparative study

\begin{tabular}{lll}
\hline Evaluation criteria & Diamond abrasive & Diode laser \\
\hline Injection & $\begin{array}{l}\text { Scared and skeptical were infiltrated } \\
\text { with local anesthesia }\end{array}$ & Only topical gel/spray was used \\
Bleeding & Moderate bleeding in all patients & No bleeding \\
Pain & High values of pain & No pain \\
Redness & Was a concern & Absolutely happy \\
Gingival color & Was a concern & Absolutely happy \\
Wound healing comfort levels & Had issues & Uneventful \\
Postoperative discomfort & Was a concern & Daily routine continued with ease \\
Medications & As need to be aroused & Not necessary at all \\
Treatment prognosis & Was partially comfortable & Absolutely comfortable \\
Recurrence of pigments in 6 months & Was seen in 3 patients & Only 1 patient had recurrence \\
\hline
\end{tabular}




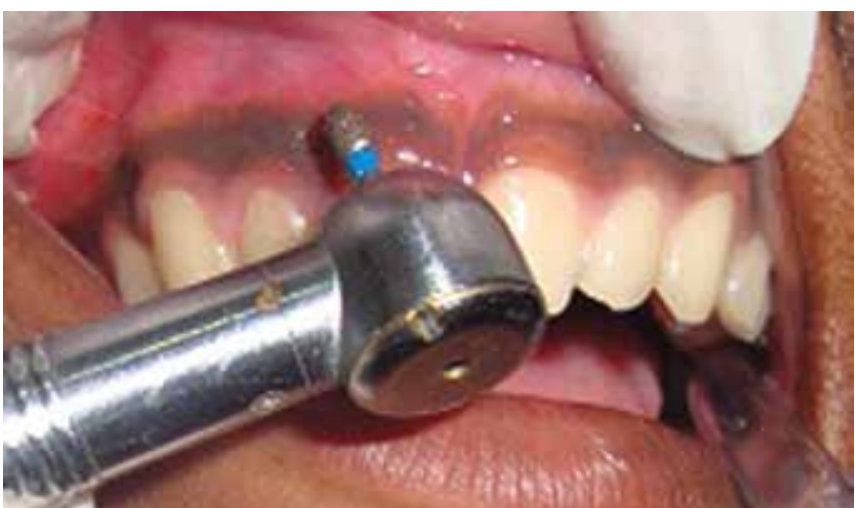

Fig. 3B: Intraoperative view of the patient while undergoing treatment on the right side with a diamond abrasive (Case 1)

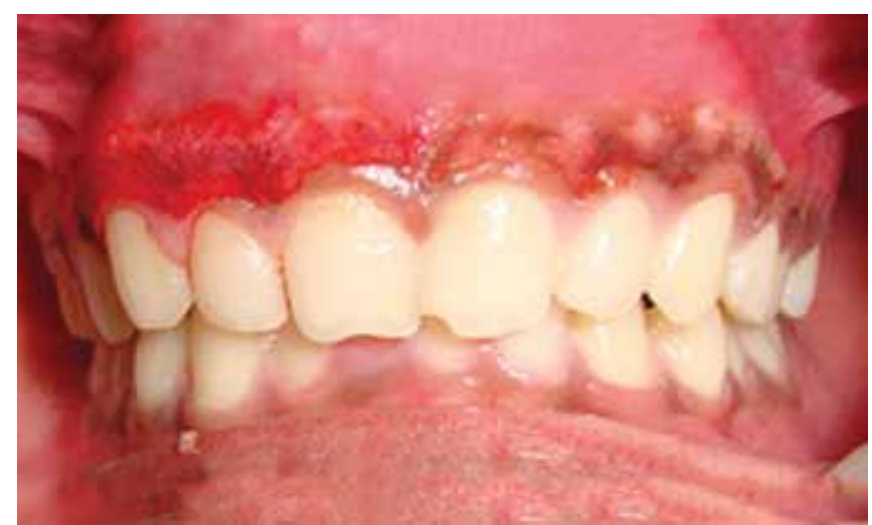

Fig. 3D: Immediate postoperative view of the patient (Case 1)

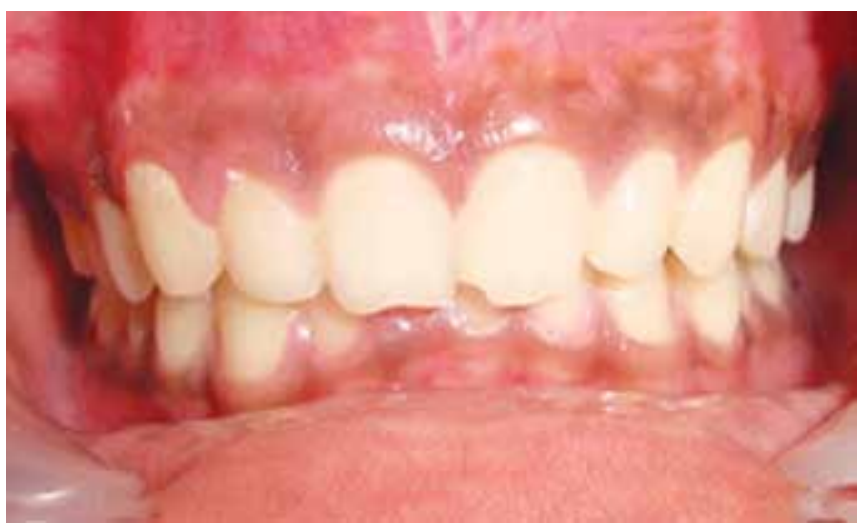

Fig. 3F: Six months postoperative view (Case 1)

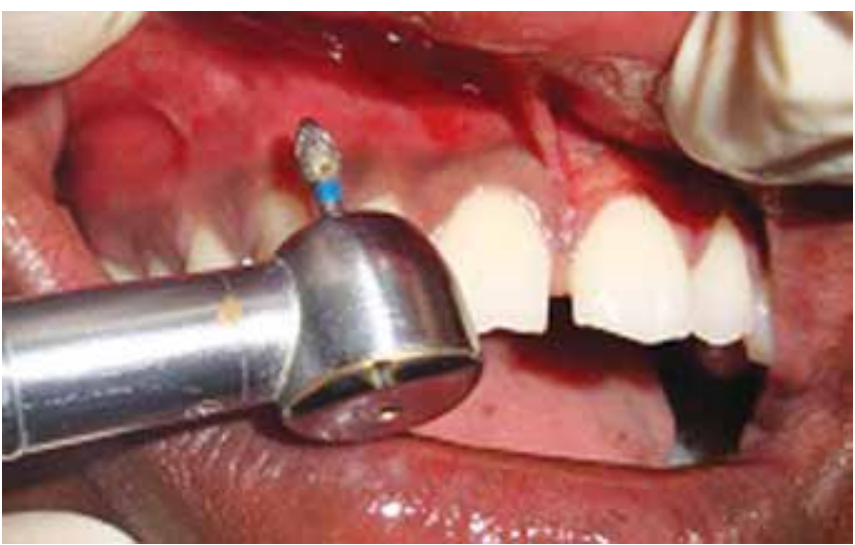

Fig. 4B: Intraoperative view of the patient while undergoing treatment on the right side with a diamond abrasive (Case 2)

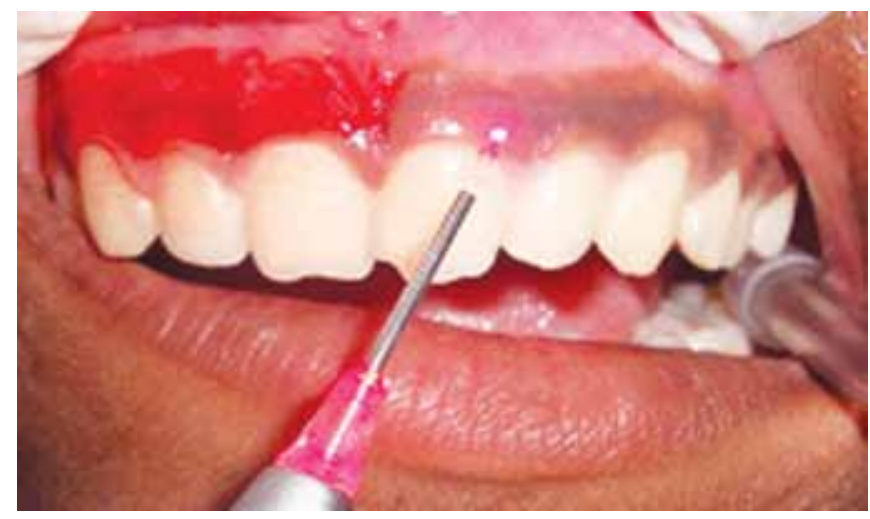

Fig. 3C: Intraoperative view of the patient while undergoing treatment on the left side with $940 \mathrm{~nm}$ diode laser (Case 1)

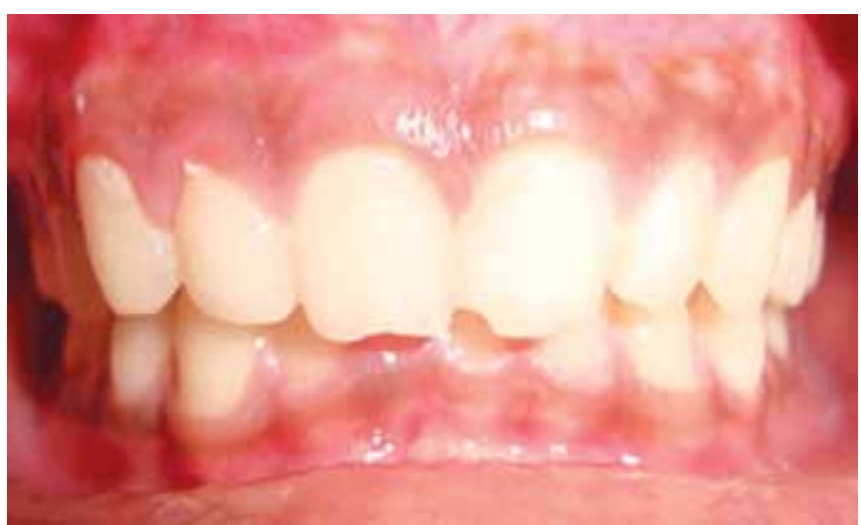

Fig. 3E: One month postoperative view (Case 1)

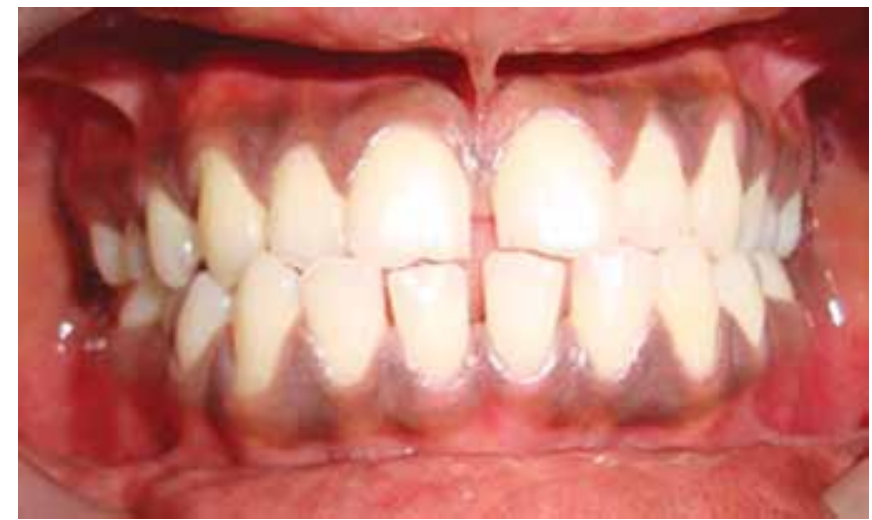

Fig. 4A: Preoperative view of the patient (Case 2)

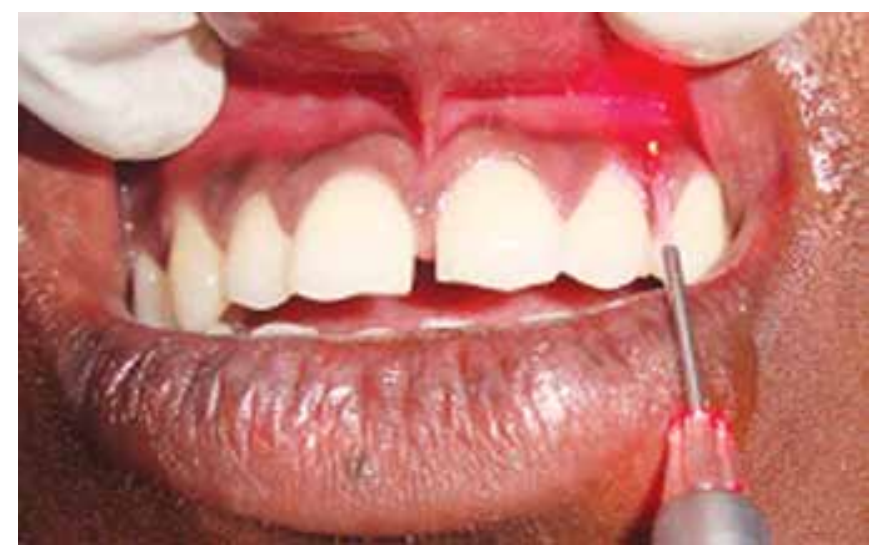

Fig. 4C: Intraoperative view of the patient while undergoing treatment on the left side with $940 \mathrm{~nm}$ diode laser (Case 2) 


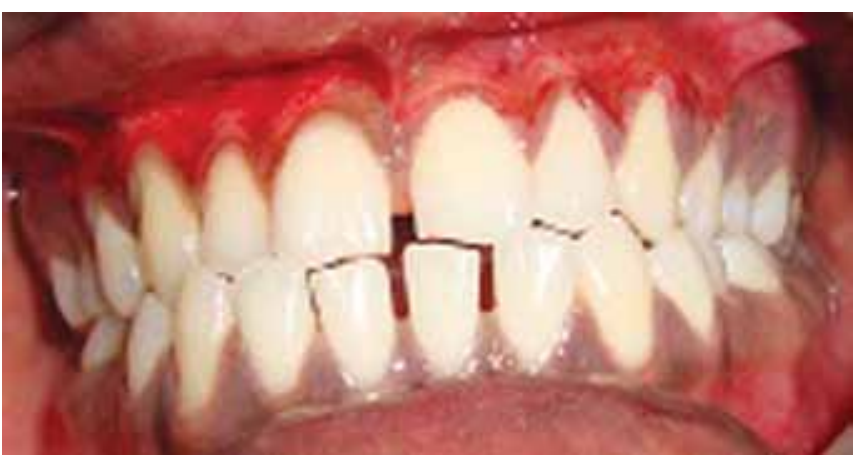

Fig. 4D: Immediate postoperative view of the patient (Case 2)

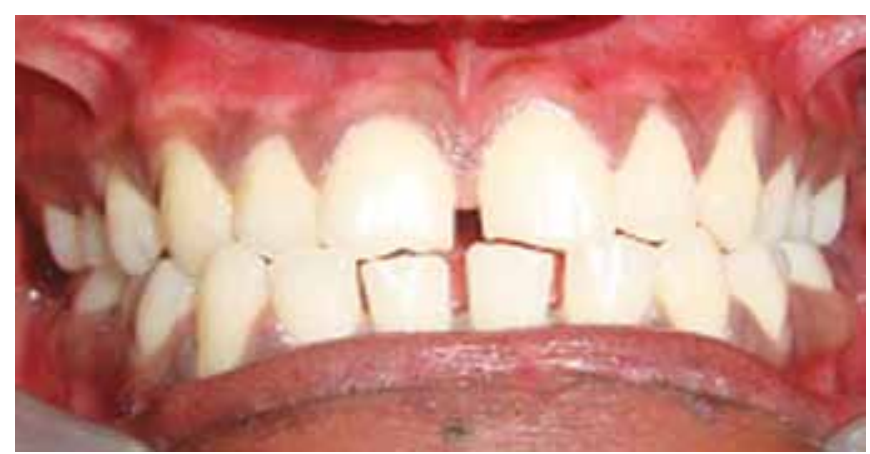

Fig. 4F: Six months postoperative view (Case 2)

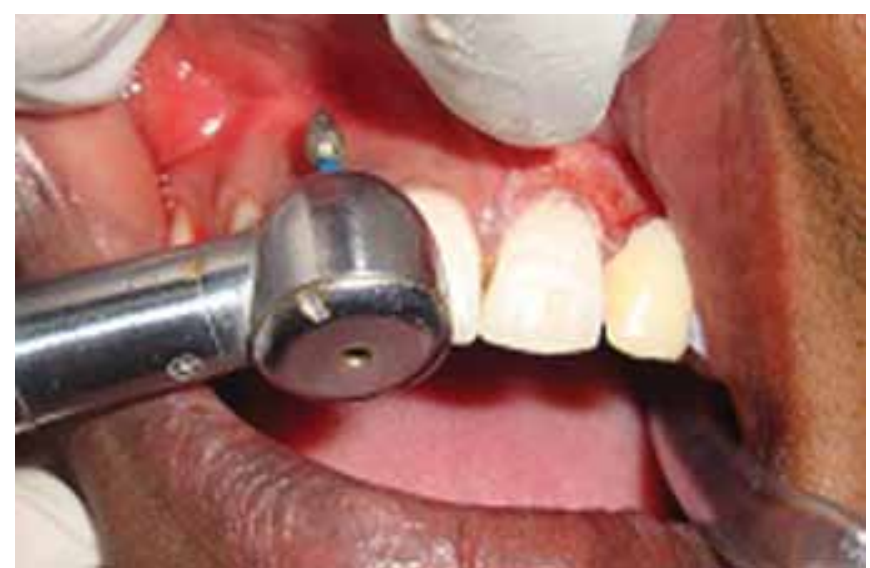

Fig. 5B: Intraoperative view of the patient while undergoing treatment on the right side with a diamond abrasive (Case 3)

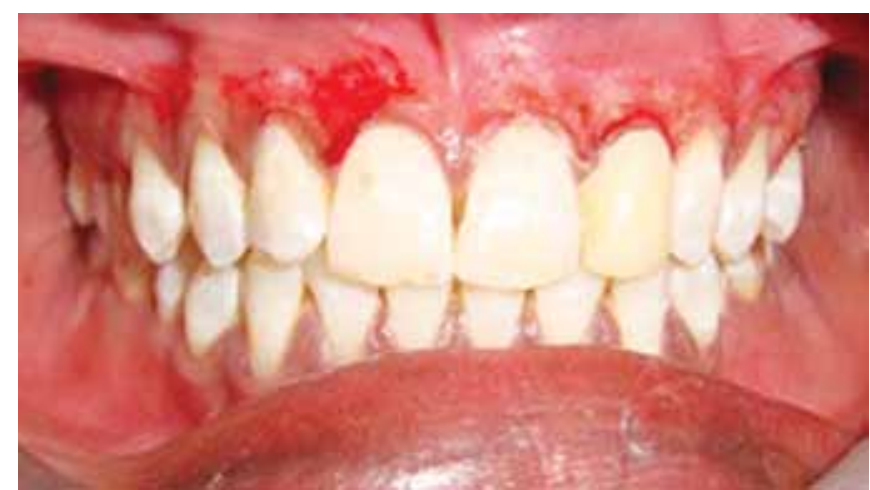

Fig. 5D: Immediate postoperative view of the patient (Case 3)

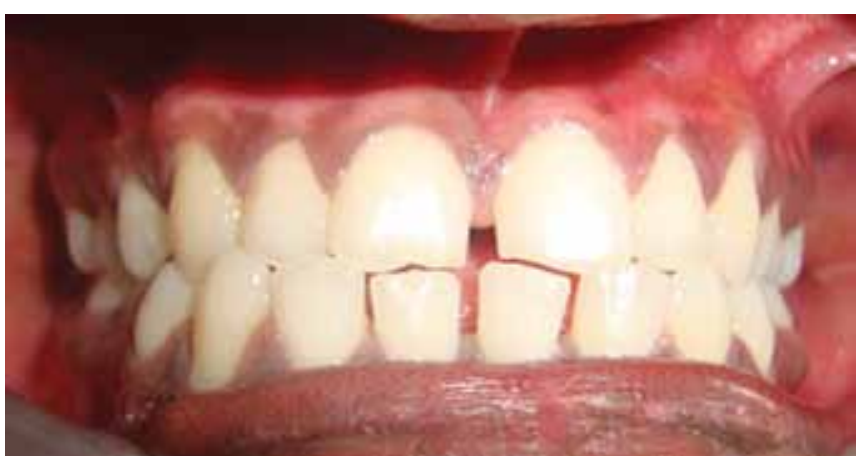

Fig. 4E: One month postoperative view (Case 2)

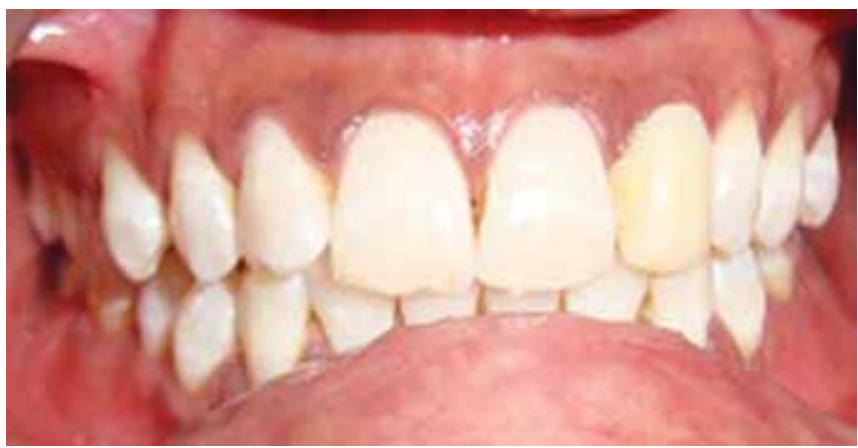

Fig. 5A: Preoperative view of the patient (Case 3)

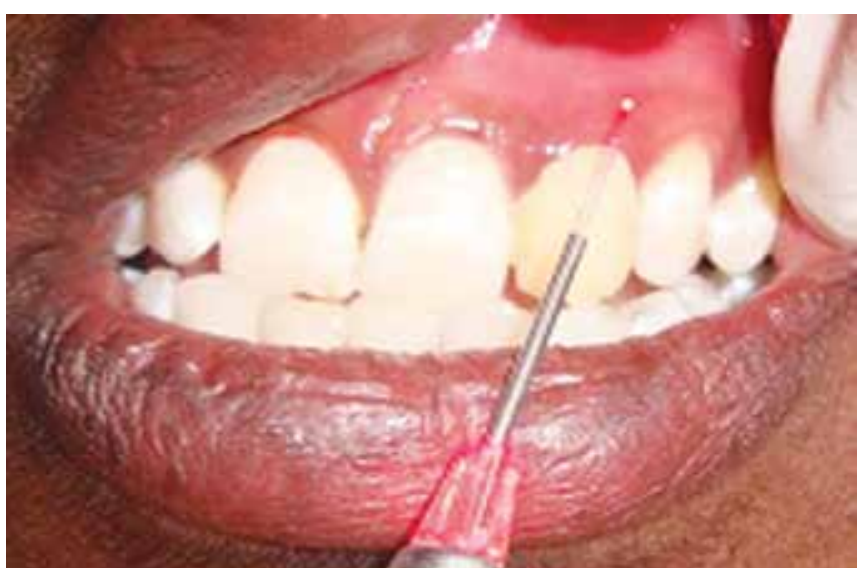

Fig. 5C: Intraoperative view of the patient while undergoing treatment on the left side with $940 \mathrm{~nm}$ diode laser (Case 3)

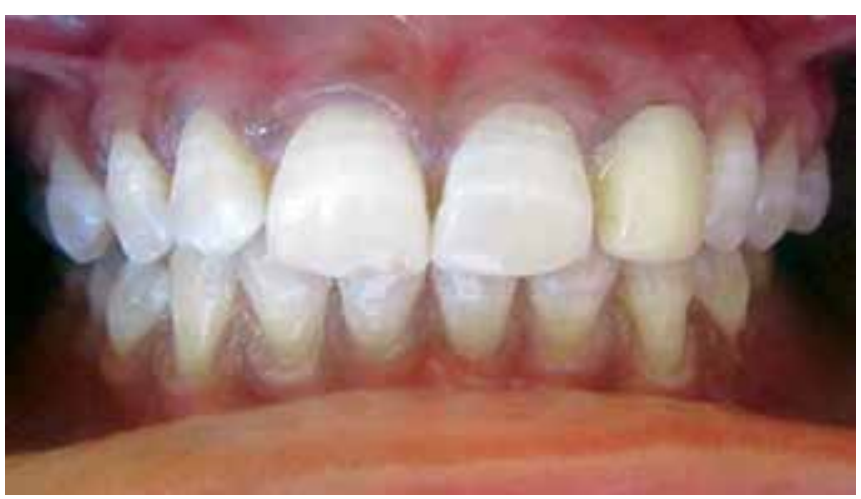

Fig. 5E: One month postoperative view (Case 3) 


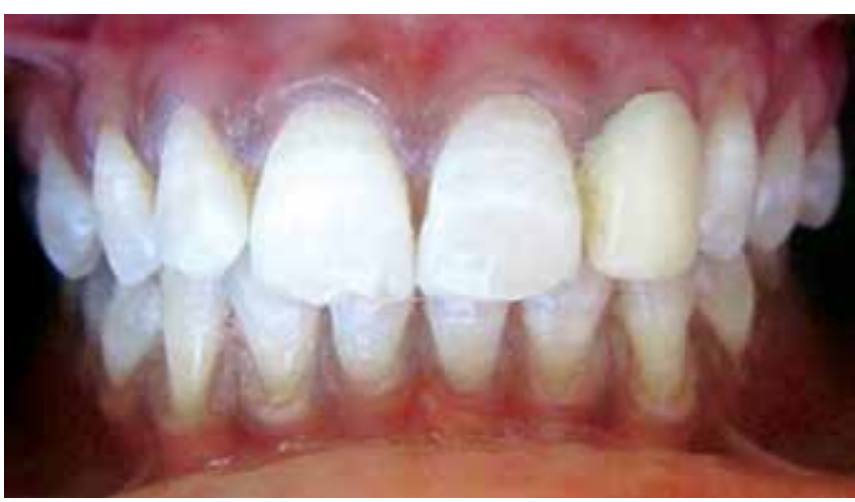

Fig. 5F: Six months postoperative view (Case 3)

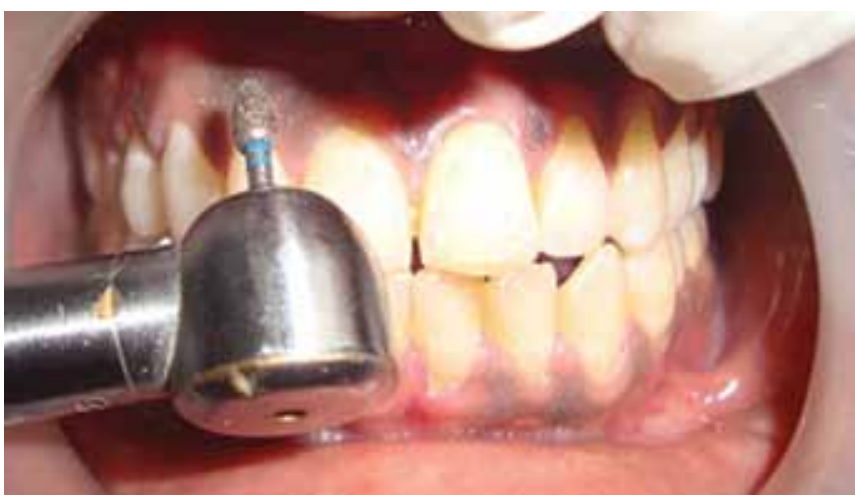

Fig. 6B: Intraoperative view of the patient while undergoing treatment on the right side with a diamond abrasive (Case 4)

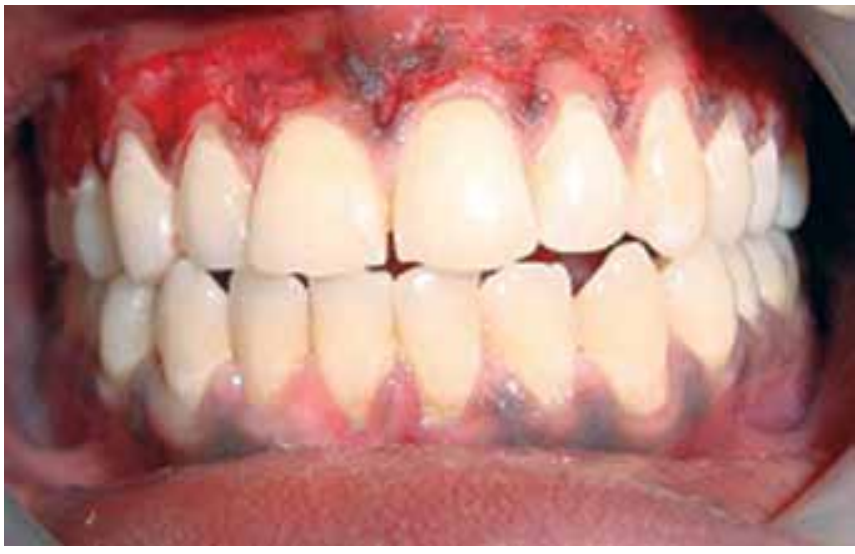

Fig. 6D: Immediate postoperative view of the patient (Case 4)

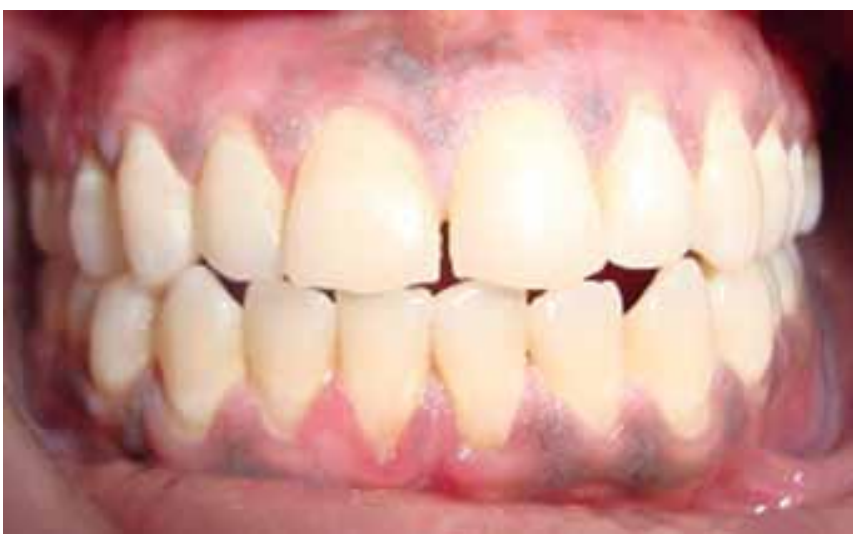

Fig. 6F: Six months postoperative view (Case 4)

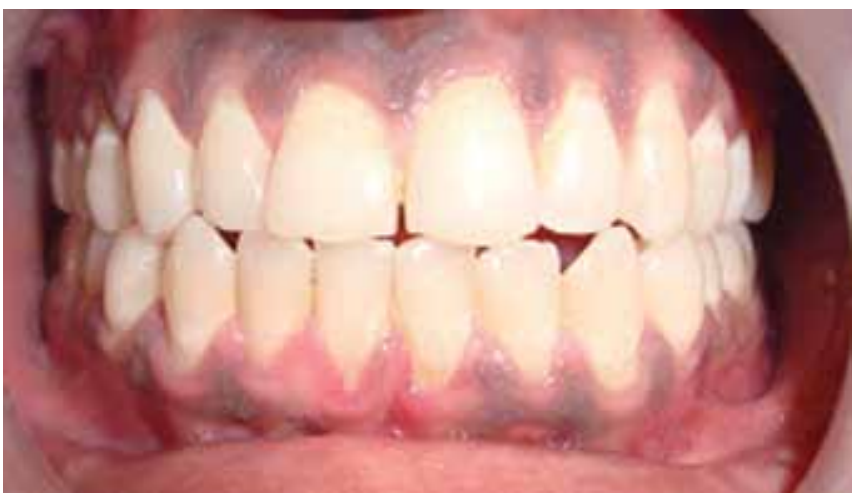

Fig. 6A: Preoperative view of the patient (Case 4)

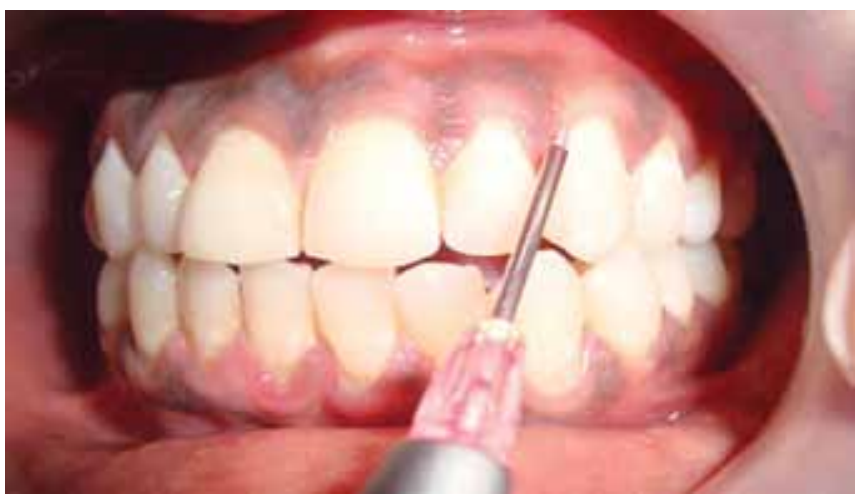

Fig. 6C: Intraoperative view of the patient while undergoing treatment on the left side with $940 \mathrm{~nm}$ diode laser (Case 4)

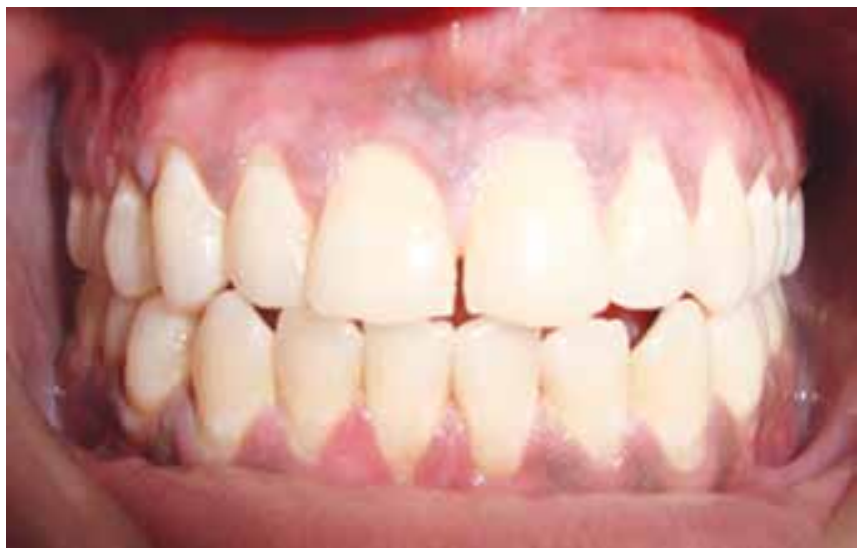

Fig. 6E: One month postoperative view (Case 4)

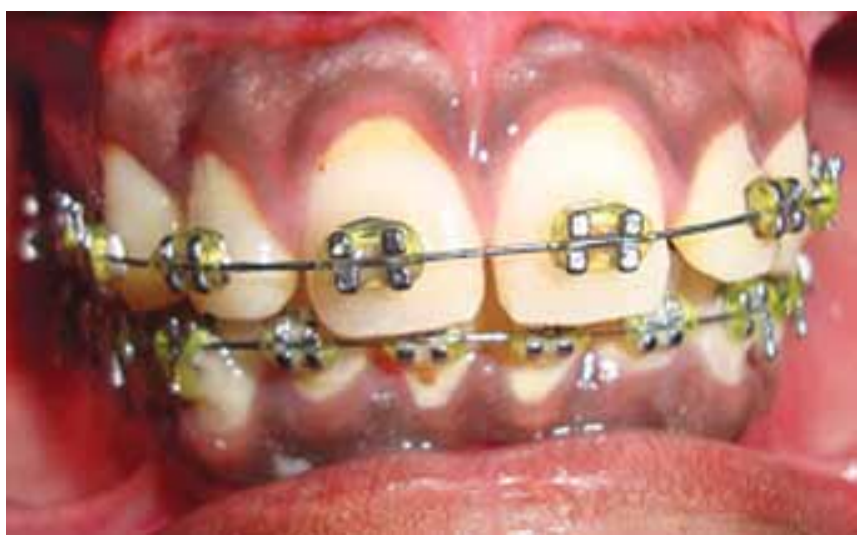

Fig. 7A: Preoperative view of the patient (Case 5) 


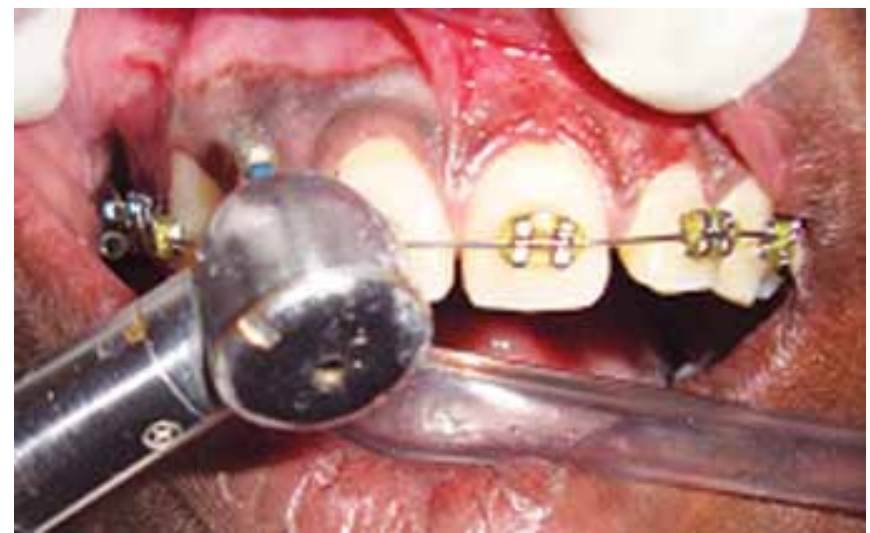

Fig. 7B: Intraoperative view of the patient while undergoing treatment on the right side with a diamond abrasive (Case 5)

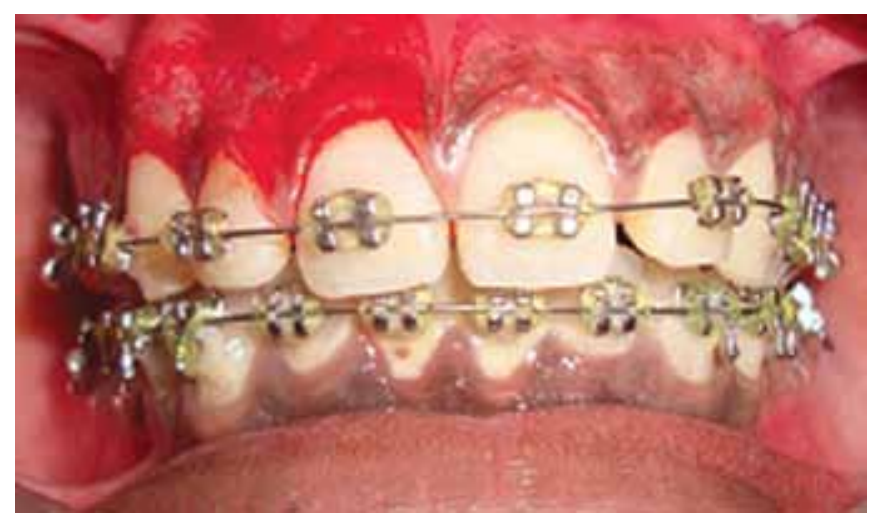

Fig. 7D: Immediate postoperative view of the patient (Case 5)

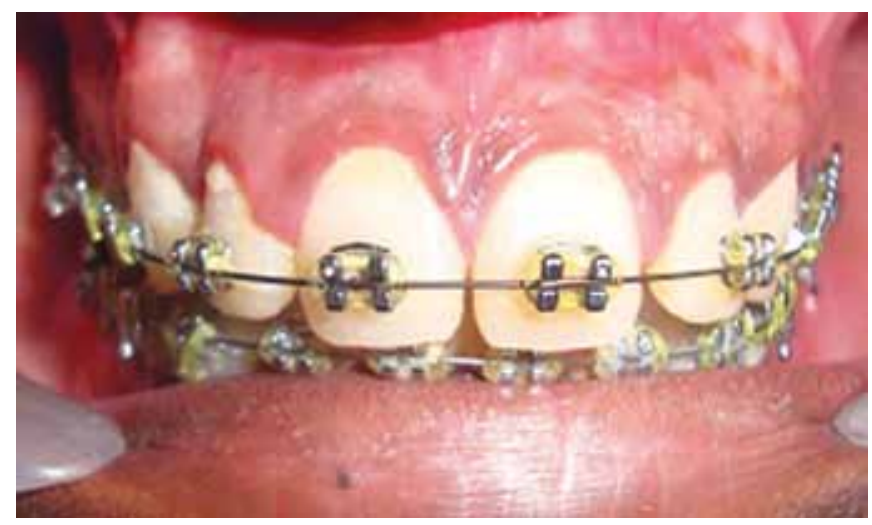

Fig. 7F: Six months postoperative view (Case 5)

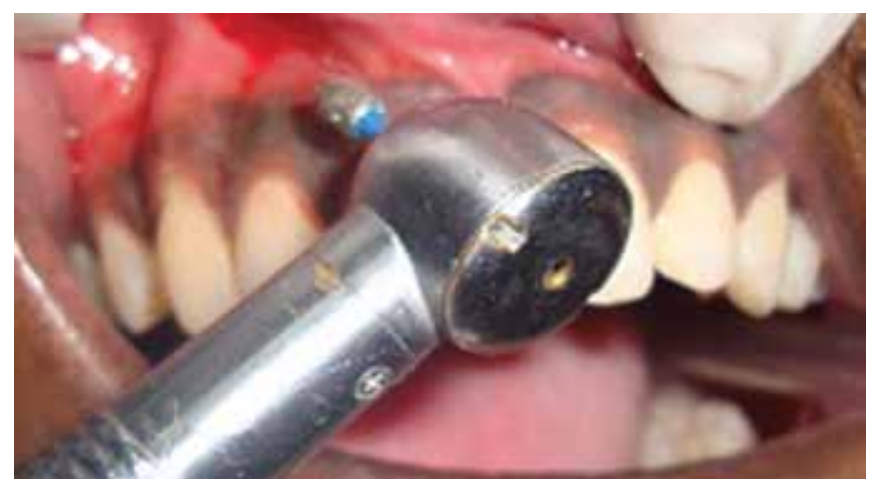

Fig. 8B: Intraoperative view of the patient while undergoing treatment on the right side with a diamond abrasive (Case 6)

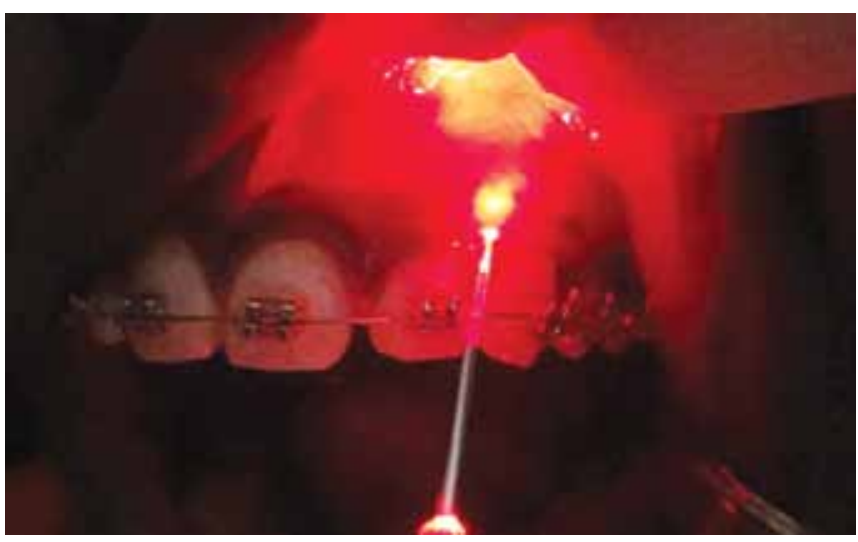

Fig. 7C: Intraoperative view of the patient while undergoing treatment on the left side with $940 \mathrm{~nm}$ diode laser (Case 5)

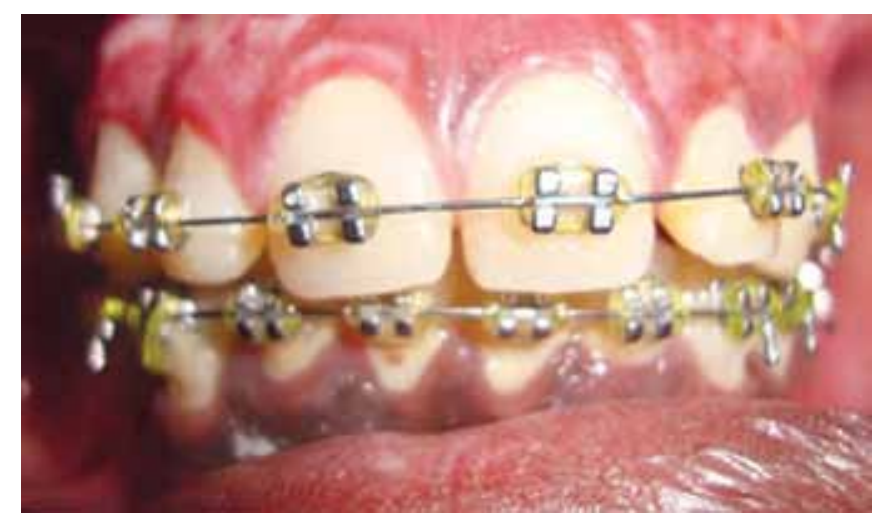

Fig. 7E: One month postoperative view (Case 5)

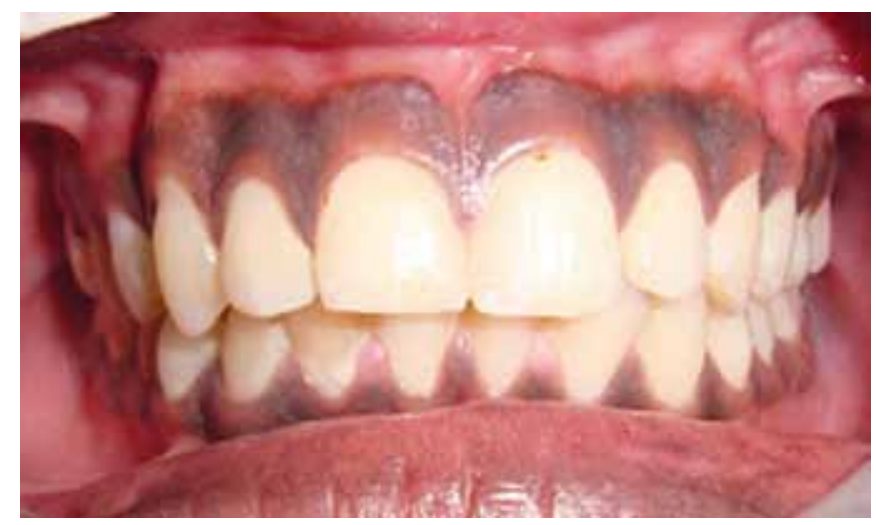

Fig. 8A: Preoperative view of the patient (Case 6)

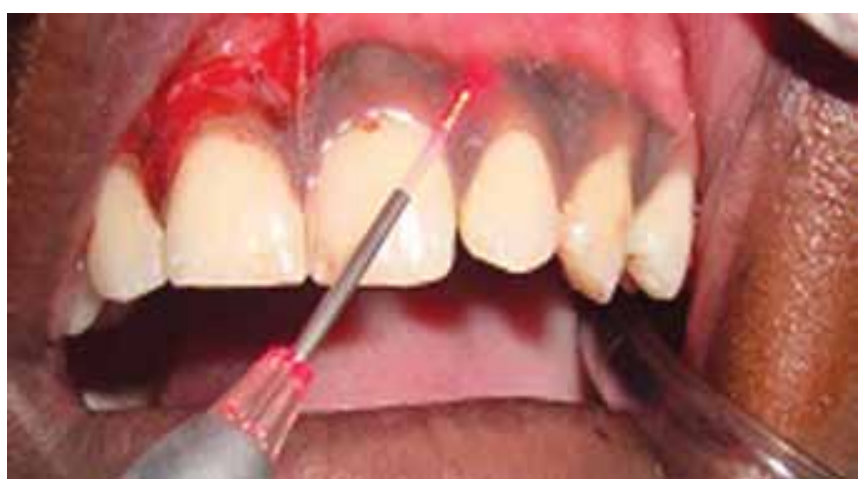

Fig. 8C: Intraoperative view of the patient while undergoing treatment on the left side with $940 \mathrm{~nm}$ diode laser (Case 6) 


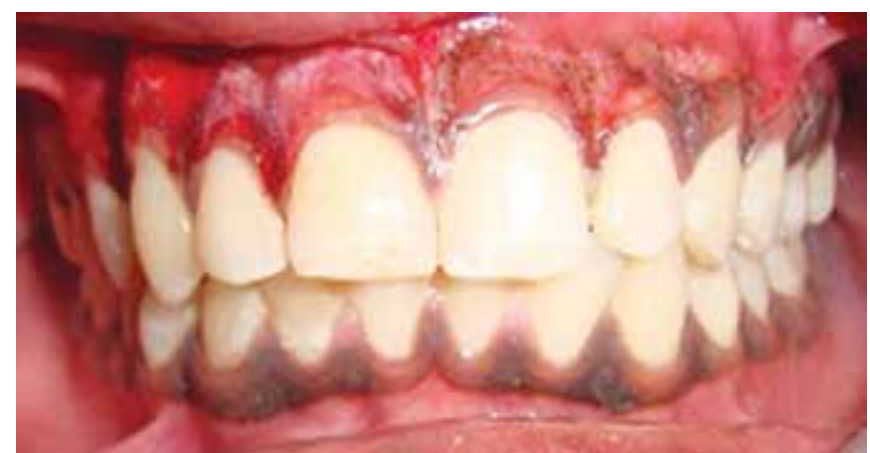

Fig. 8D: Immediate postoperative view of the patient (Case 6)

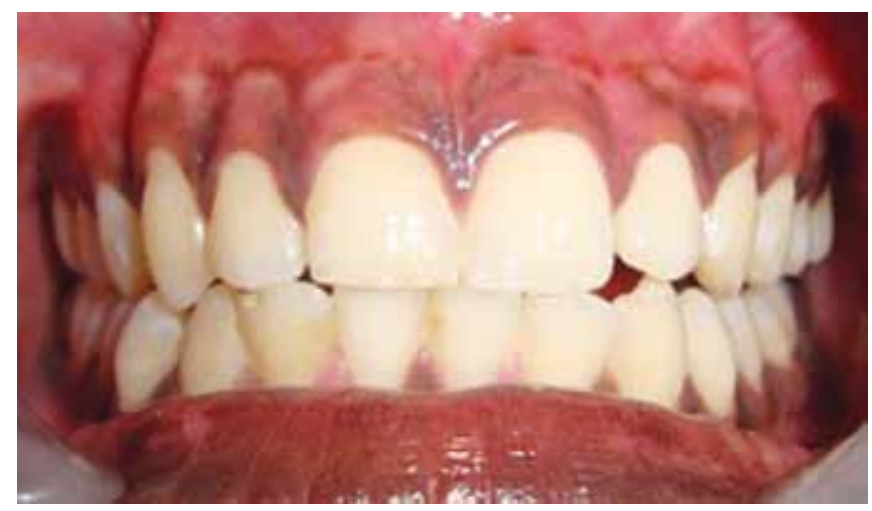

Fig. 8F: Six months postoperative view (Case 6)

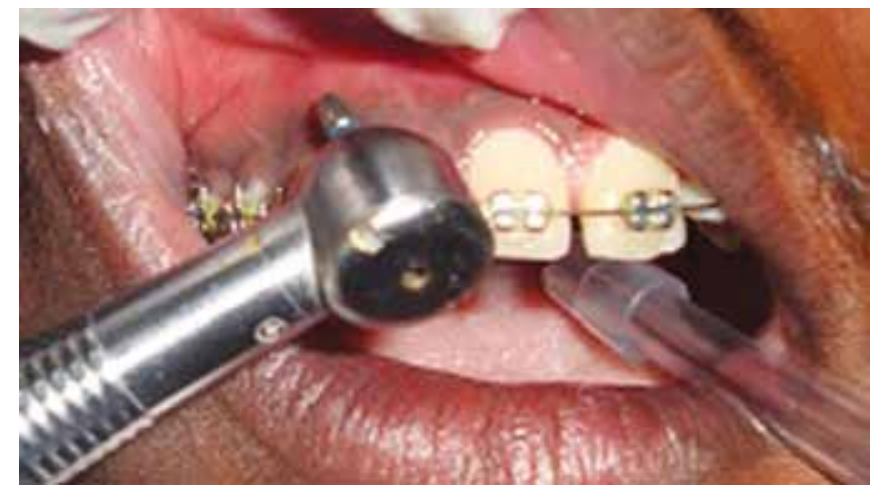

Fig. 9B: Intraoperative view of the patient while undergoing treatment on the right side with a diamond abrasive (Case 7)

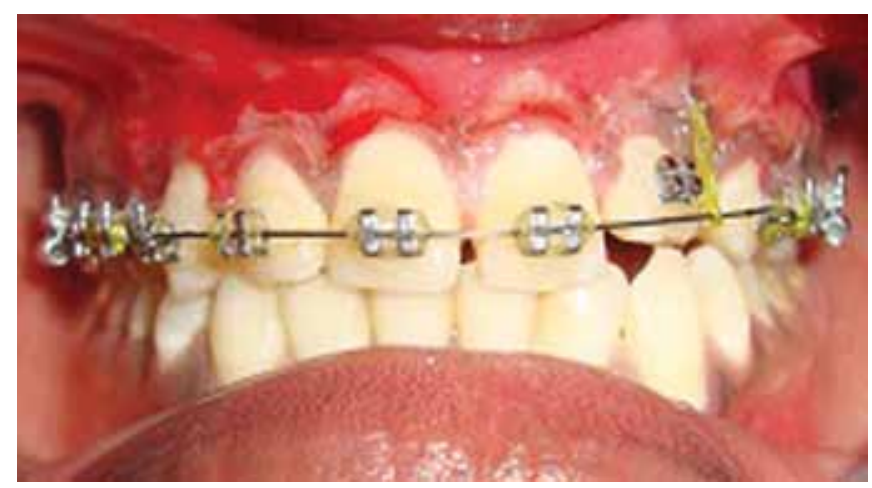

Fig. 9D: Immediate postoperative view of the patient (Case 7)

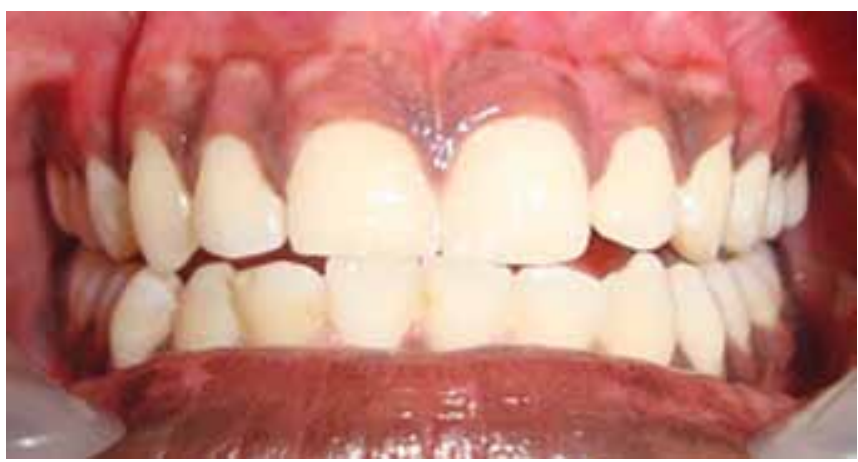

Fig. 8E: One month postoperative view (Case 6)

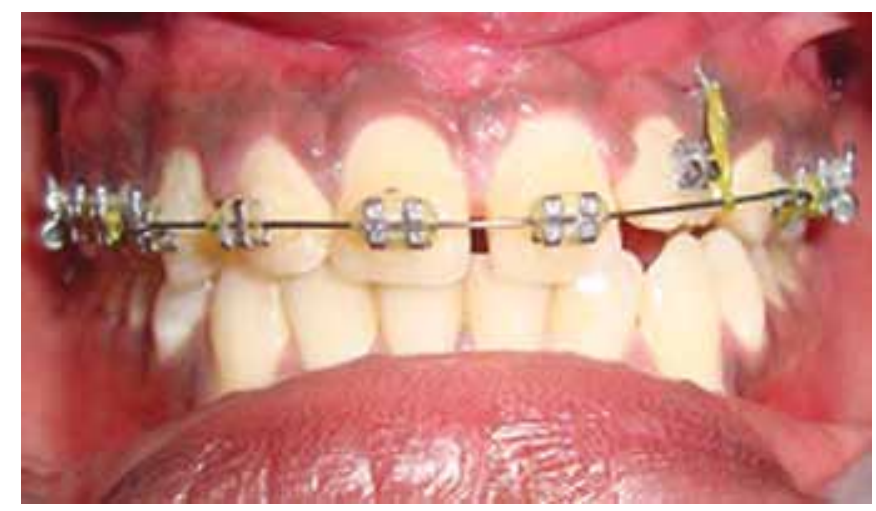

Fig. 9A: Preoperative view of the patient (Case 7)

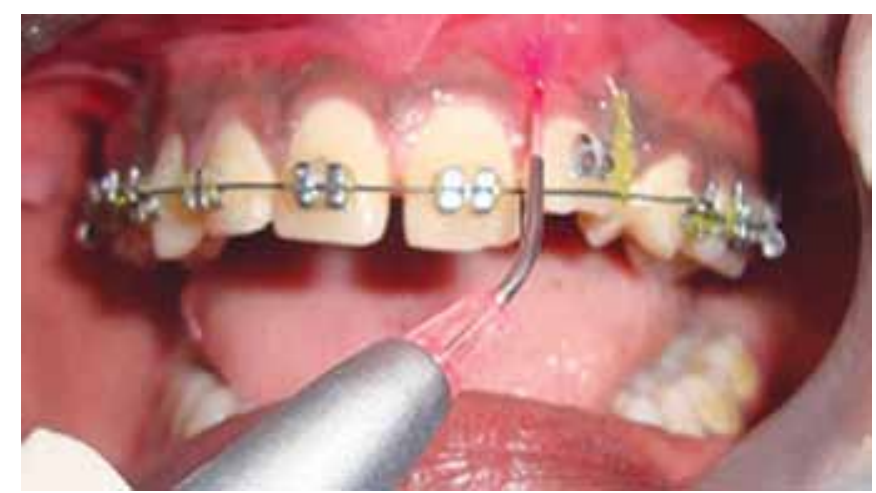

Fig. 9C: Intraoperative view of the patient while undergoing treatment on the left side with $940 \mathrm{~nm}$ diode laser (Case 7)

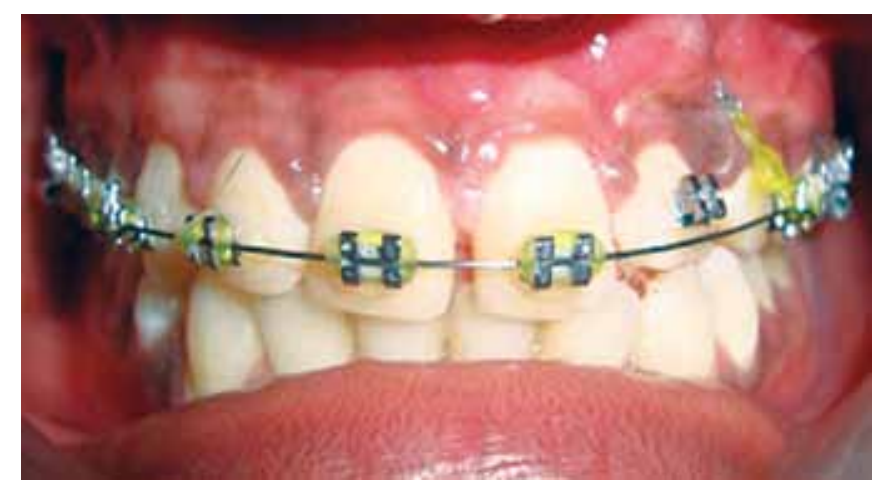

Fig. 9E: One month postoperative view (Case 7) 


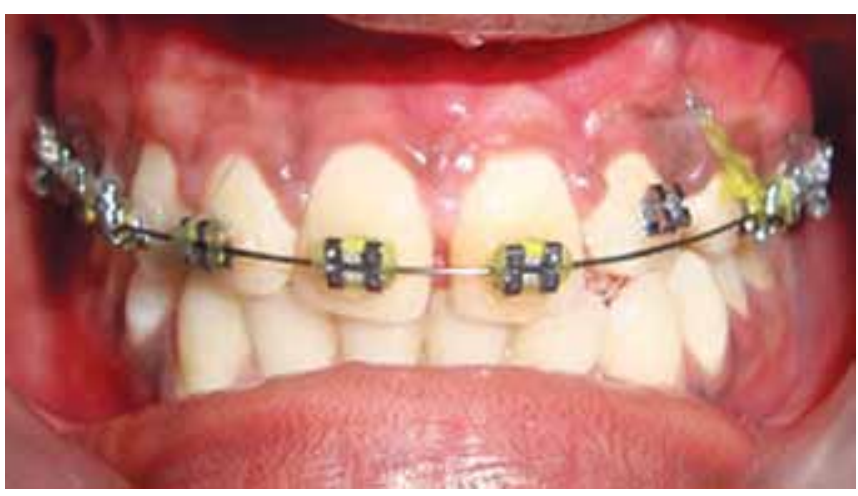

Fig. 9F: Six months postoperative view (Case 7)

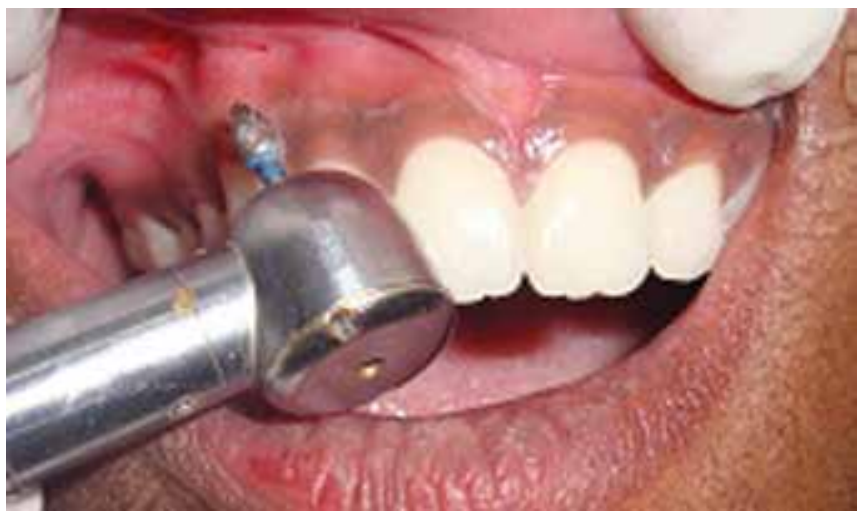

Fig. 10B: Intraoperative view of the patient while undergoing treatment on the right side with a diamond abrasive (Case 8)

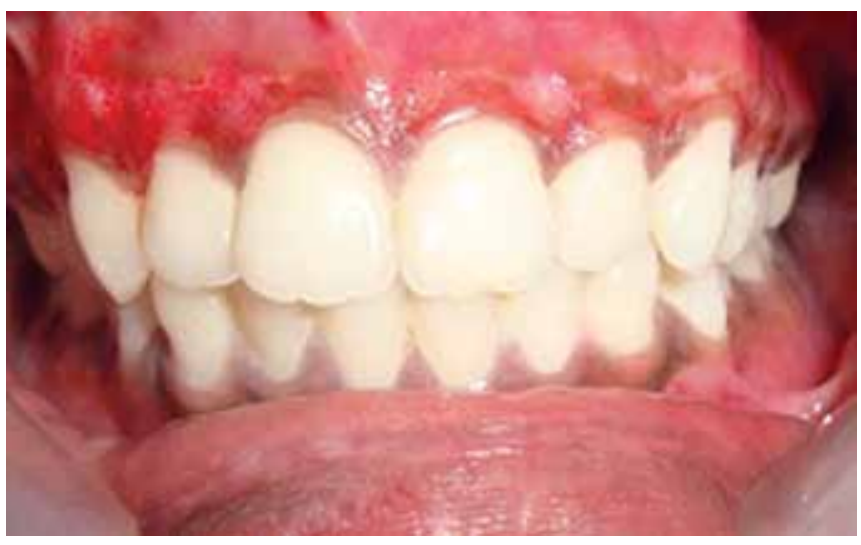

Fig. 10D: Immediate postoperative view of the patient (Case 8)

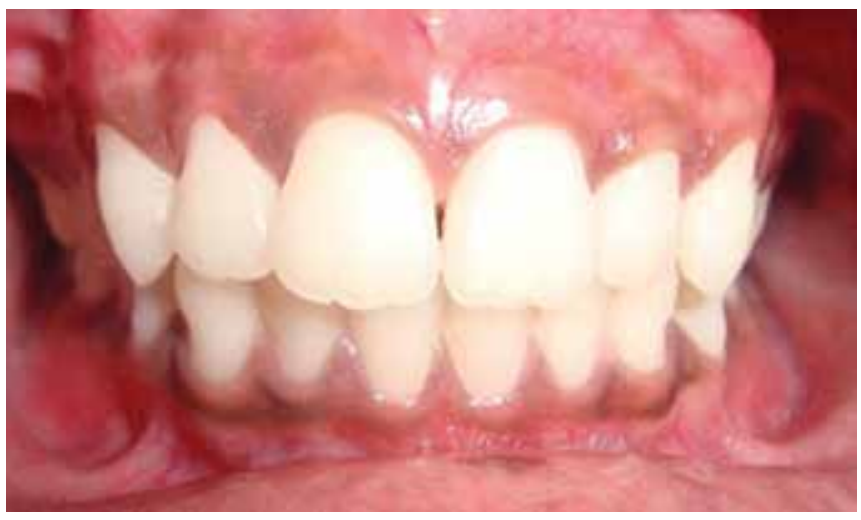

Fig. 10F: Six months postoperative view (Case 8)

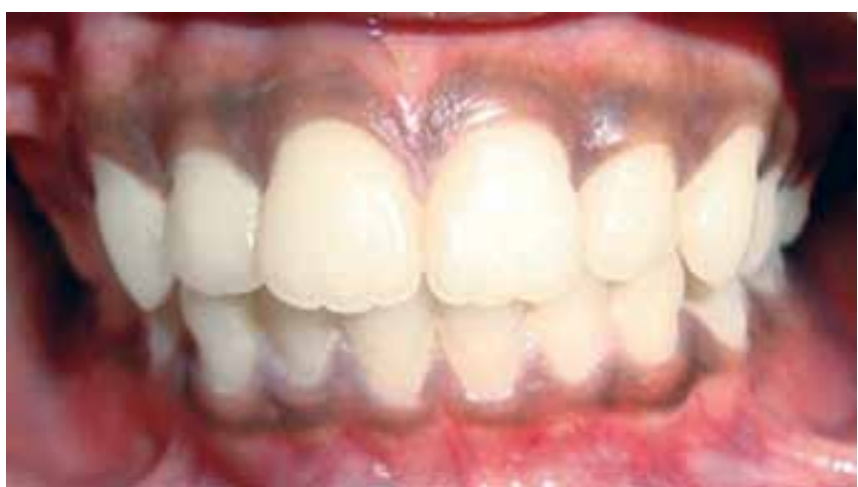

Fig. 10A: Preoperative view of the patient (Case 8)

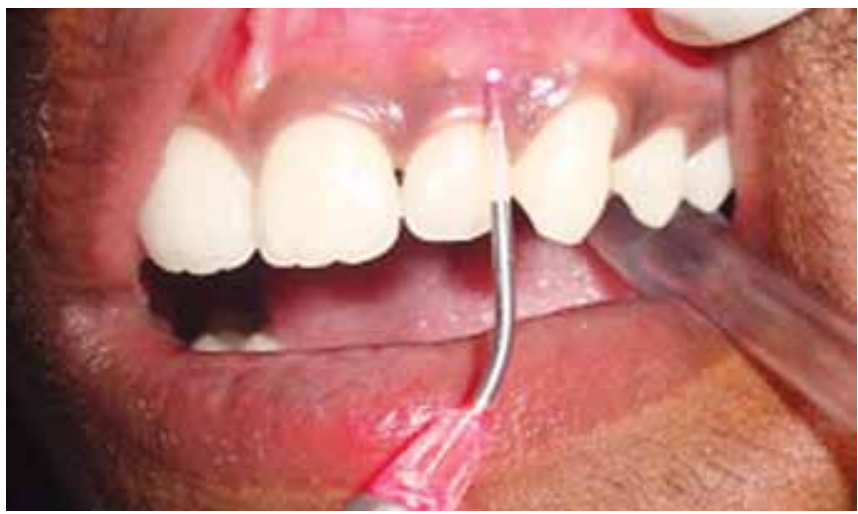

Fig. 10C: Intraoperative view of the patient while undergoing treatment on the left side with $940 \mathrm{~nm}$ diode laser (Case 8)

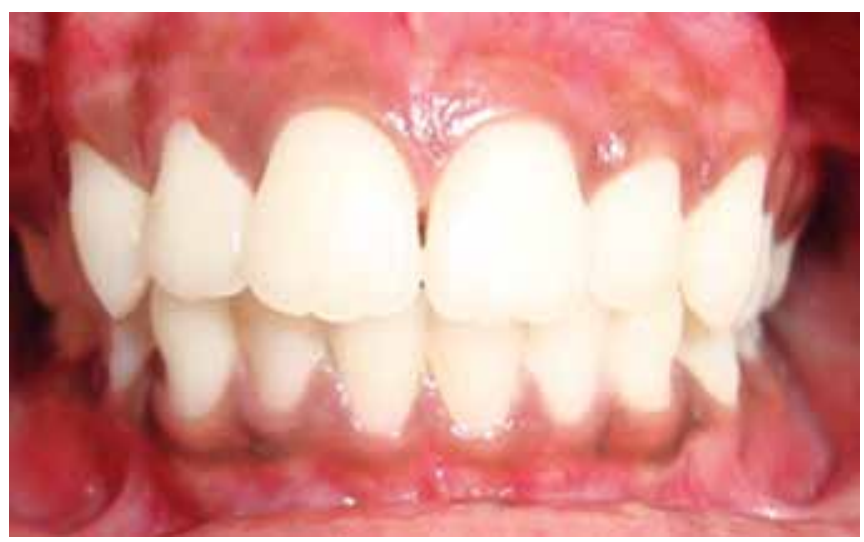

Fig. 10E: One month postoperative view (Case 8)

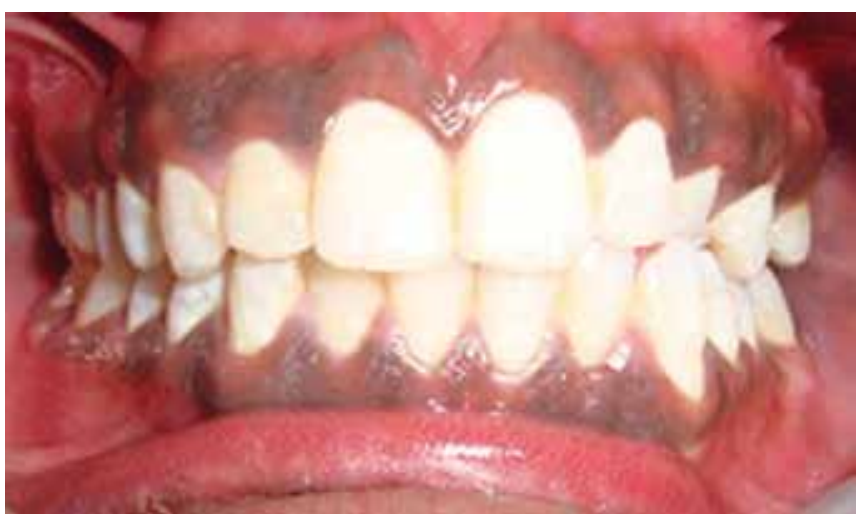

Fig. 11A: Preoperative view of the patient (Case 9) 


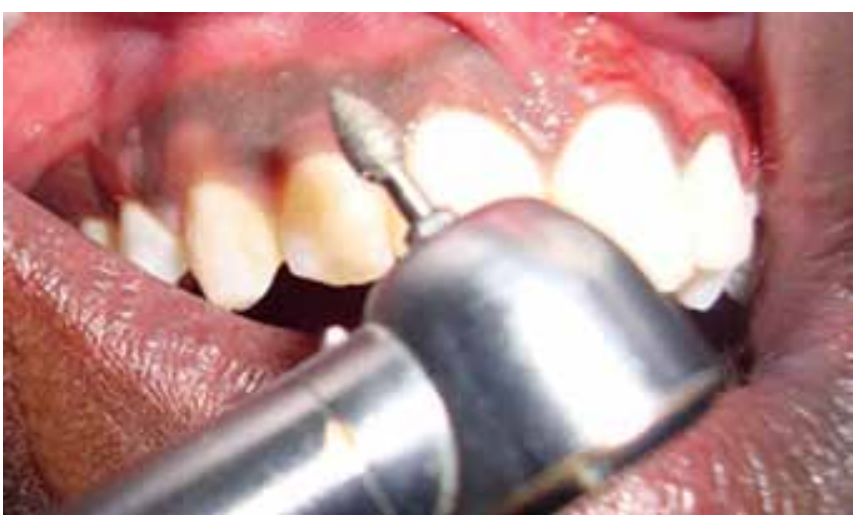

Fig. 11B: Intraoperative view of the patient while undergoing treatment on the right side with a diamond abrasive (Case 9)

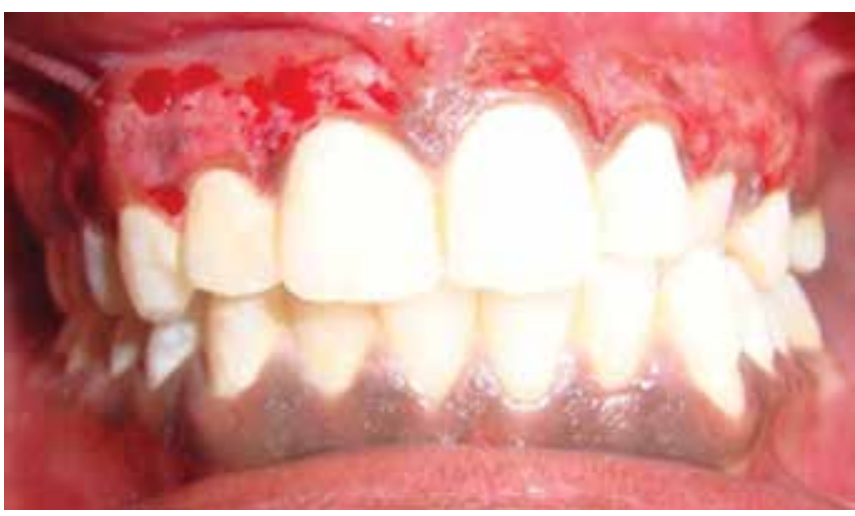

Fig. 11D: Immediate postoperative view of the patient (Case 9)

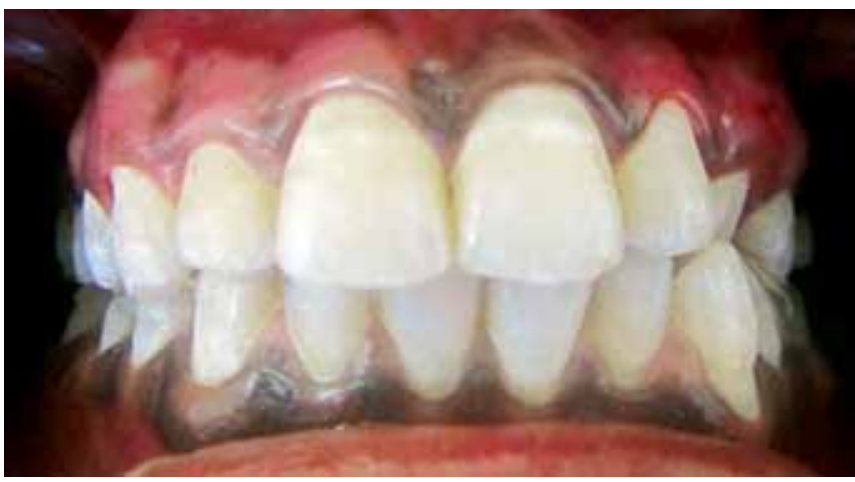

Fig. 11F: Six months postoperative view (Case 9)

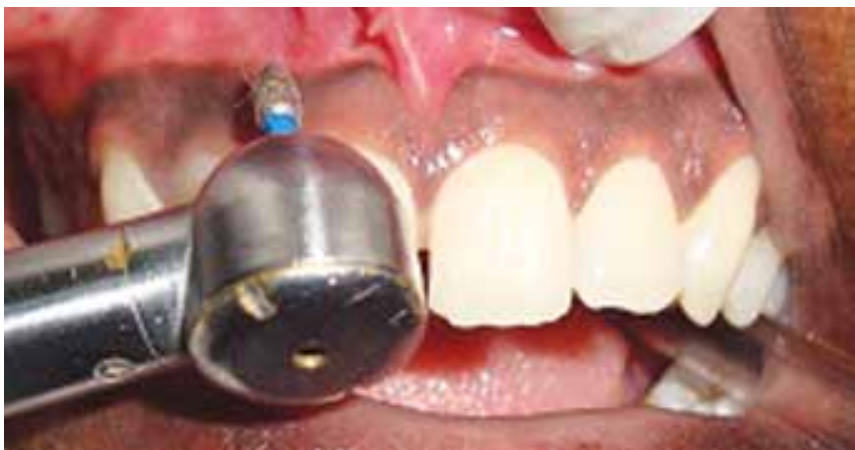

Fig. 12B: Intraoperative view of the patient while undergoing treatment on the right side with a diamond abrasive (Case 10)

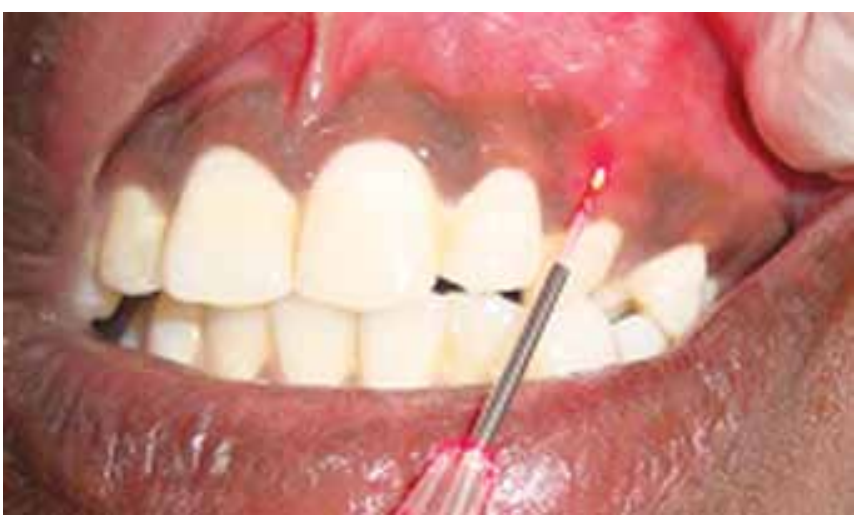

Fig. 11C: Intraoperative view of the patient while undergoing treatment on the left side with $940 \mathrm{~nm}$ diode laser (Case 9)

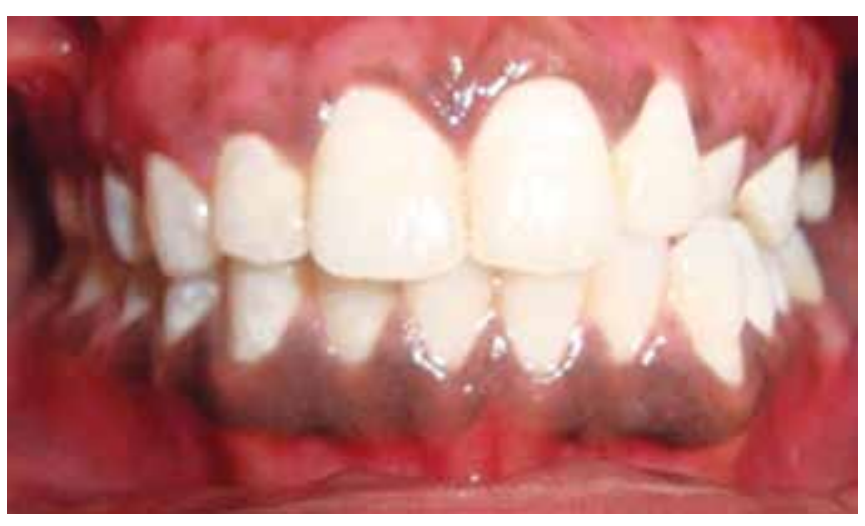

Fig. 11E: One month postoperative view (Case 9)

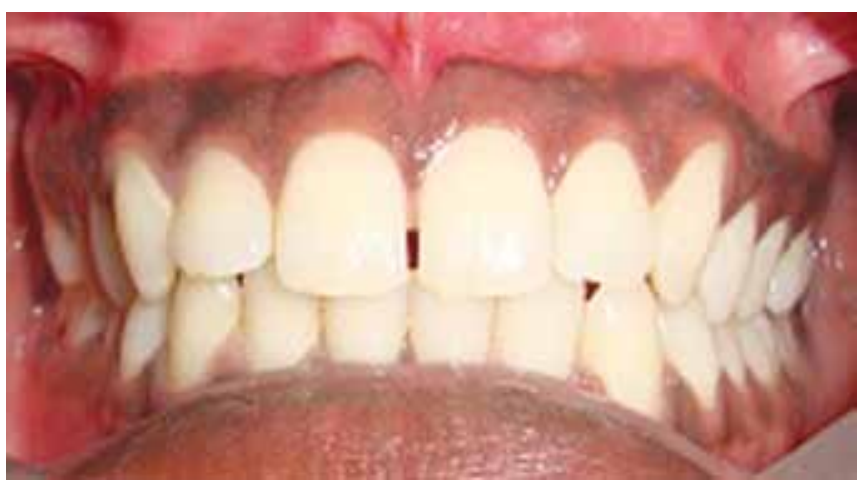

Fig. 12A: Preoperative view of the patient (Case 10)

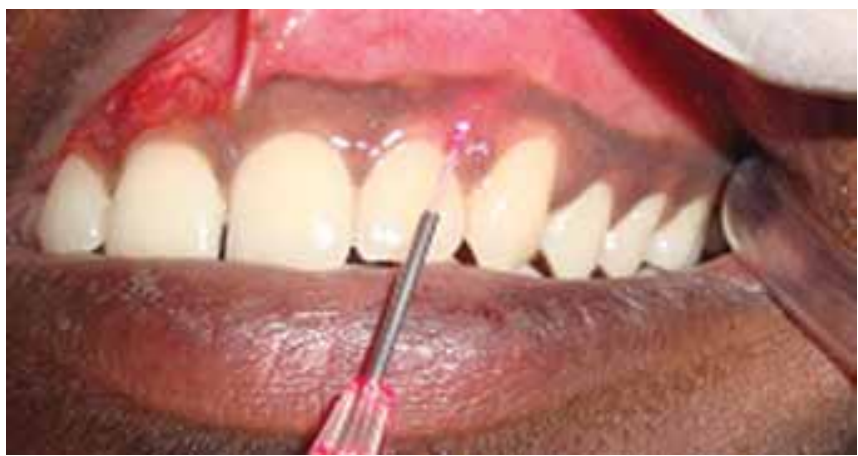

Fig. 12C: Intraoperative view of the patient while undergoing treatment on the left side with $940 \mathrm{~nm}$ diode laser (Case 10) 


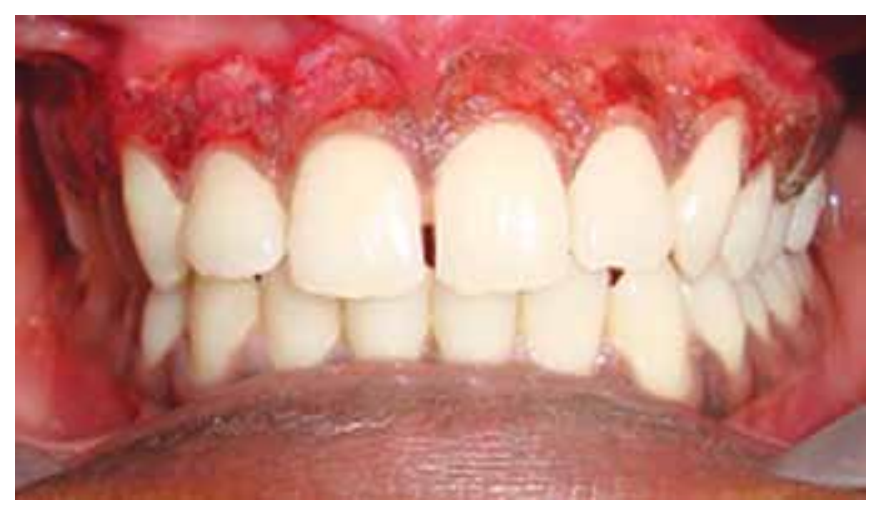

Fig. 12D: Immediate postoperative view of the patient (Case 10)

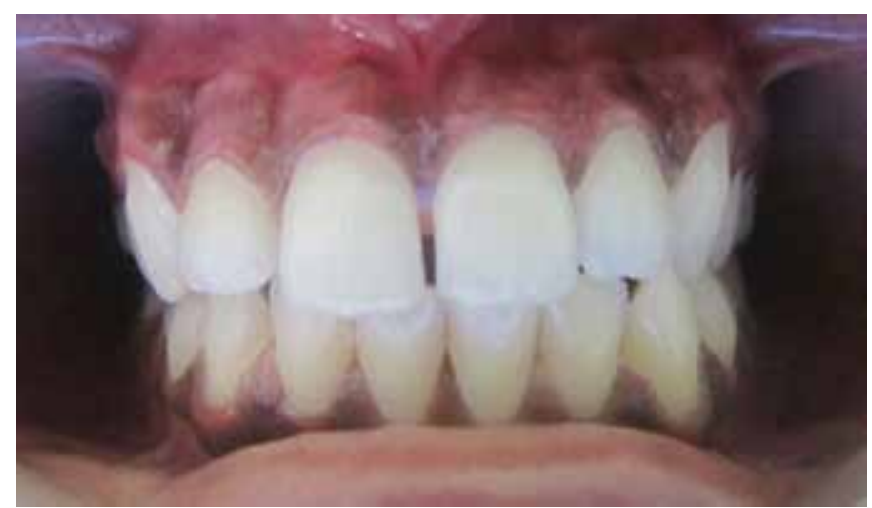

Fig. 12F: Six months postoperative view (Case 10)

lymphatic vessels thereby reducing the swelling and pain in the surgical site.

All patients complained of redness, gingival color moderation and severe soreness with postoperative discomfort in the initial 24 hours in the right side. Various studies (Radvar et al 1995, Midda et al in 1992 and Pinero et al 1997) have stated that the interaction of the laser energy with the pigmented portion of the bacteria ${ }^{19}$ reduces bacterial population at the surgical site. Oral cavity is flooded with microbial flora and its reduction on the laser ablated surgical site aids in comfort levels in patients as lasers are bactericidal in nature. Several mouthwashes can also be prescribed postoperatively to reduce the contamination of the surgical site. Hence, five out of 10 patients were not happy with the wound healing ${ }^{20}$ process on the right side, whereas all of them were excited with the uneventful healing on the left quadrant.

Five out of 10 patients had taken medication to reduce the pain during the healing period and also applied some topical medicated gels (Hexigel, ICPA Health Products, India) on the right side. The total treatment period and the prognosis were monitored in all patients for 6 months postoperatively. The recurrence pattern and rate was also quantified. Three out of 10 patients had recurrence of some melanin pigmentation in the right side, and only one patient showed the reappearance of pigments on the laser treated site. This could be due to the level of highly pigmented gingiva in the patient as compared to the rest in the study group.

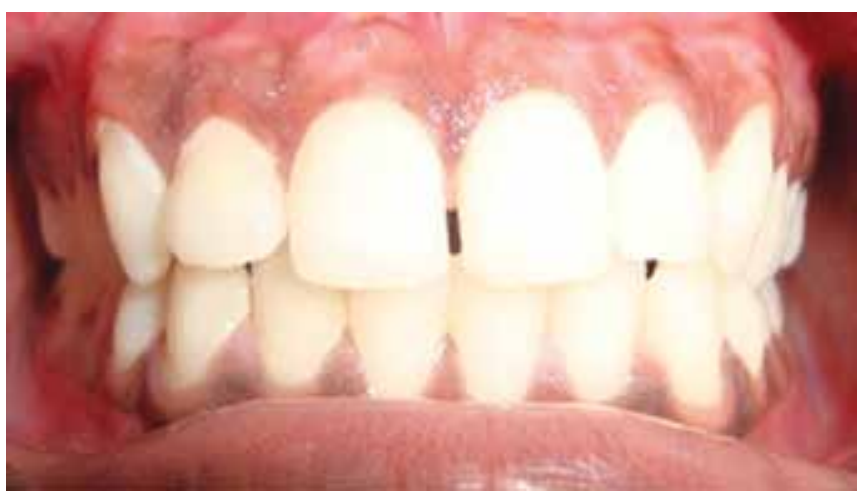

Fig. 12E: One month postoperative view (Case 10)

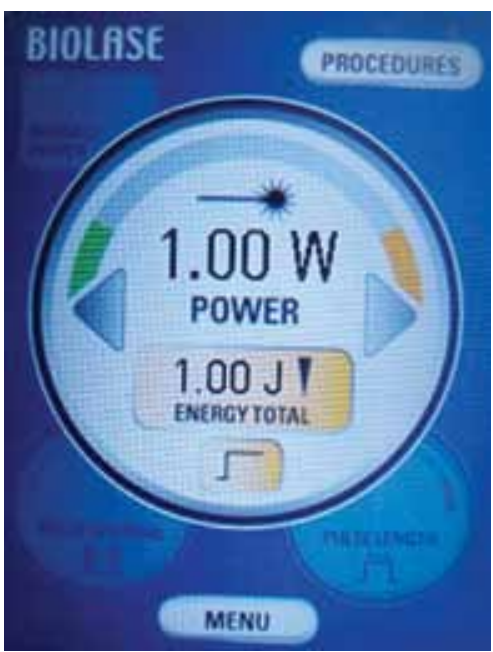

Fig. 13: Laser parameters on the control panel of $940 \mathrm{~nm}$ diode

All patients unanimously agreed to the fact that diode di,22 $^{21}$ lasers had indeed given them a pain-free, hassle-free treatment option in today's high-tech modern dentistry. The fast paced life of people further enhanced the use of lasers in such day to day esthetic ${ }^{23}$ procedures for quick and fast healing period.

\section{CONCLUSION}

The patients related the benefits of lasers as advantages and, hence, welcomed this paradigm shift to pain-free dentistry. Lasers have made clinical dentistry comfortable, affordable and stress free for both the patients and doctor. The results are promising, predictable and definitely rewarding. Immediate adaptation to regular daily routine is the trump card and acts in favor of lasers. The laser procedure itself excels in minimal or no usage of injection, minimal bleeding and comfort reducing the psychological fear associated with esthetic dentistry.

\section{ACKNOWLEDGMENT}

We would like to thank all the patients for being a part of this 6 months study. 


\section{REFERENCES}

1. Baiju CS, Khashu H, Manchand S. Comparative clinical evaluation of gingival depigmentation using scalpel and diode laser: case series. Solaze J Laser Dent 2011 April;5(1):11-17.

2. Romanos GE, Nentwig GH. Diode laser (980 nm) in oral and maxillofacial surgical procedures: clinical observations based on clinical applications. J Clin Laser Med Surg 1999;17:193-197.

3. Kreisler M, Meyer C, Stender E, Daublander M, WillershausenZonnchen B, d'Hoedt B. Effect of diode laser irradiation on the attachment rate of periodontal ligament cells: an in vitro study. J Periodontal 2001;72(10):1312-1317.

4. Yousuf A, Hossain M, Nakamura Y, Yamada Y, Kinoshita J, Mastsumoto K. Removal of gingival melanin pigmentation with the semiconductor diode laser: a case report. J Clin Laser Med Surg 2000;18:263-266.

5. Gutknecht N, Kanehi S, Moritz A, Mittermayer C, Lampert F. Effects of Nd:YAG-laser irradiation on monolayer cell cultures. Lasers Surg Med 1998;22:30-36.

6. Rao P. Depigmentation of gingiva - a step by step procedure, with the use of Er:YAG laser - a case report. Solaze J Laser Dent 2011 April;5(1):29-30.

7. Doshi Y, Khandage N, Byakod G, Patil P. Management of gingival pigmentation with diode laser: is it a predictive tool? Int J Laser Dent 2012 Jan-April;2(1):29-32.

8. Parker S. Lasers and soft tissue: periodontal therapy. British Dental J 2007 Mar 24;202(6):309-315.

9. Aoki A, Sasaki KM, Watanabe H, Ishikawa I. Lasers in nonsurgical periodontal therapy. Periodont 2000;36:59-97.

10. Cobb CM. Lasers in Periodontics: Use and abuse. Compend Contin Educ Dent 1997;18:847-860.

11. Thukral S, Thukral N, Jain S, Tambwekar S. Lasers in periodontal soft tissue surgeries. Solaze J Laser Dent 2009 Jan;3(1):15-18.
12. Gutknecht N, Zimmermann R, Lampert F. Lasers in Periodontology: state of the art. J Oral Laser Applications 2001; 1:169-179.

13. Stabholz A, Zeltser R, Sela M, Peretz B, Moshonov J, Ziskind D. The use of lasers in dentistry: principles of operation and clinical application. Compendium 2003;24:811-824.

14. Merchant NF. Merchant S. Laser-assisted depigmentation procedure: a case report. Solaze J Laser Dent 2010 March;4(1): 35-36.

15. Parker S. Lasers and soft tissue: 'loose' soft tissue surgery. British Dental J 2007 Feb 24;202(4):185-191.

16. Sharon E, Azaz B, Ulmansky M. Vaporization of melanin in oral tissues and skin with a carbon dioxide laser: a canine study. J Oral Maxillofac Surg 2000;58:1387-1393. Discussion 1393-1394.

17. Parker S. Low-level laser use in dentistry. British Dental J 2007 Feb 10;202(3):131-138.

18. Medrado RAP, Pudliese LS, Reis SRA, Andreade ZAA. The influence of low level laser therapy on wound healing and its biological action upon myofibroblasts. Lasers Surg Med 2003;32(3): 239-244.

19. Moritz A, Gutknecht N, Doertbudak O, Goharkhay K, Schoop U, Schauer P, Sperr W. Bacterial reduction in periodontal pockets through irradiation with a diode laser: a pilot study. J Clin Laser Med Surg 1997;15(1):33-37.

20. Woodruff LD, Bounkeo J, Brannon WM, Dawesk KS, et al. The efficacy of laser therapy in wound repair: a meta-analysis of the literature. Photomedicine and Laser Surgery 2004;22(3): 241-247.

21. Kher U. Diode lasers: the cutting edge. International J Laser Dent 2011 Sep-Dec;1(1):49-53.

22. Goharkhay K, Moritz A, Wilder-Smith P, Schoop U, Kluger W, Jakolitsch S, Sperr W. Effects on oral soft tissue produced by a diode laser in vitro. J Oral Surg 1978;36:932-937.

23. Iyer VH. Laser-assisted pink esthetic management for an orthodontic patient. Int J Laser Dent 2013;3(1):33-36. 